\begin{tabular}{|c|l|}
\hline Title & Precipitation of various oxides in ODS ferritic steels \\
\hline Author(s) & Oono, N. H.; Ukai, S.; Tominaga, K.; Ebisawa, N.; Tomura, K. \\
\hline Citation & Journal of materials science, 54(11), 8786-8799 \\
\hline https://doi.org/L0.1007/s10853-019-03516-6 \\
\hline Issue Date & 2019-06 \\
\hline Doc URL & http://hdl.handle.net/2115//8328 \\
\hline Rights & The final publication is available at link.springer.com \\
\hline Type & article (author version) \\
\hline File Information & manuscript_ref_fix_revised.pdf \\
\hline
\end{tabular}

Instructions for use 


\section{Precipitation of various oxides in ODS ferritic steels}

N.H. Oono ${ }^{1, \text { a }, ~ S . ~ U k a i ~}{ }^{1, \text { b }}$, K. Tominaga ${ }^{1}$, N. Ebisawa ${ }^{2, \text { c }}$, K. Tomura ${ }^{2, \mathrm{~d}}$

${ }^{1}$ Faculty, Graduate School and School of Engineering, Hokkaido University, Sapporo 060-8628, Japan

${ }^{2}$ International Research Center for Nuclear Materials Science, Institute for Materials Research, Tohoku University, Oarai 311-1313, Japan

an-oono@eng.hokudai.ac.jp

bs-ukai@eng.hokudai.ac.jp

cnaoki.ebisawa@imr.tohoku.ac.jp

dkeiko.tomura@imr.tohoku.ac.jp

Corresponding author: Naoko OONO-HORI

Faculty, Graduate School and School of Engineering, Hokkaido University, Kita 13, Nishi 8, Kita-ku, Sapporo, Hokkaido 060-8628, Japan

E-mail : n-oono@eng.hokudai.ac.jp

Tel.: +81 117066356 


\begin{abstract}
The reactive elements ( $\mathrm{Ti}, \mathrm{Al}$ and $\mathrm{Zr}$ ) have been widely used for the improvement of the strength or the oxide resistance of ODS steels. In the present work, we studied the effect of the reactive elements on the precipitation of oxide particles, especially focusing upon the appropriate amount of the oxide composing elements, by addition of the large amounts of $\mathrm{Y}_{2} \mathrm{O}_{3}$ and reactive elements. The mechanically alloyed powders are annealed in a wide temperature range from $773 \mathrm{~K}$ to $1423 \mathrm{~K}$, and then analyzed by various analysis method (small angle X-ray scattering and X-ray diffraction by synchrotron radiation X-ray, scanning transmission electron microscope combined with energy dispersion X-ray spectroscopy, high-resolution transmission microscopy and 3D-atom probe). Ti, $\mathrm{Al}$ and $\mathrm{Zr}$ enhanced the growth of oxide particles, opposite to the many literature of $\mathrm{Ti}$ and $\mathrm{Zr}$ added ODS steels, as a result of the addition of $\mathrm{Y}_{2} \mathrm{O}_{3}$ and these elements ten times larger than those for usual use. The nucleation and growth of oxide particles are discussed by simulating the critical radius of nucleation and the growth based on the LSW theory. $\mathrm{Y}_{4} \mathrm{Zr}_{3} \mathrm{O}_{12}$ is stable and easy to precipitate even at lower annealing temperature. All reactive elements enhance the growth of oxide particles because of their big molar volume as compared to that of $\mathrm{Y}_{2} \mathrm{O}_{3}$.
\end{abstract}

\title{
Keywords
}

ODS steel, reactive elements, complex oxide, precipitation 


\section{Introduction}

Oxide dispersion strengthened (ODS) steels have been developed for nuclear applications: fuel claddings of fast reactors [1-3], plasma-facing components of future fusion reactors [4-7]. After the Fukushima Daiichi nuclear disaster, an application of FeCrAl-based ODS ferritic steels as an accident-tolerant fuel cladding (ATF) for light water reactors is to be taken under consideration in Japan [8]. ODS steels have excellent high-temperature strength and irradiation resistance because of the fine oxide particles dispersed in the steel matrix. The type of oxide varies depending on the adding elements. $\mathrm{Y}_{2} \mathrm{O}_{3}$ is typical oxide which is added at the beginning of mechanical alloying (MA). Oxide particles are formed by decomposition of $\mathrm{Y}_{2} \mathrm{O}_{3}$ during $\mathrm{MA}$ and its re-precipitation with the added solutes during subsequent consolidation [9-11]. Ti-added ODS steels have been studied most widely because the Ti addition makes finer Y-Ti complex oxide particles or clusters than $\mathrm{Y}_{2} \mathrm{O}_{3}$ particles and increases the strength of ODS steels [12-15], and the structure and the mechanism of precipitation of oxide particles have become clearer by recent literature: by transmission electron microscopy (TEM) observation [16-18], 3Datom probe (3DAP) [19, 20], several techniques using synchrotron radiation $[9,10,21]$ and computer simulation [22]. However, the effect of adding reactive elements on the precipitation of oxide particles is still questionable, e.g. for the appropriate amount of these reactive elements, and the systematic model of precipitation is needed for the fabrication process of ODS steels. This paper focuses upon the effect of the reactive elements on the precipitation of oxide particles and the difference of precipitation between the various oxide particles, treating the addition of large amounts of the elements which compose the oxide particles. 


\section{Experimental}

Throughout this paper the specimen composition is expressed in mass percent. The base composition of the material in this study was Fe-15Cr-2W-3.5 $\mathrm{Y}_{2} \mathrm{O}_{3}$. The addition of $\mathrm{Y}_{2} \mathrm{O}_{3}$ is approximately ten times larger than that commonly reported in the literature to detect the crystal structure of oxide particles clearly with the X-ray scattering (XRD). Four different compositions were prepared to obtain various oxide particles: base, $1.5 \mathrm{Ti}$, 3Al and 3.82Zr (in this paper, we call the specimens by the total amount of added reactive elements). The amount of $\mathrm{Ti}, \mathrm{Al}$ and $\mathrm{Zr}$ was chosen enough to react with 3.5 wt. $\% \mathrm{Y}_{2} \mathrm{O}_{3}$ and form $\mathrm{Y}$-M complex oxides ( $\mathrm{M}$ is $\mathrm{Ti}, \mathrm{Al}$ and $\mathrm{Zr}$ ). Furthermore, to form the appropriate Y-M complex oxides, each oxygen concentration in the 1.5Ti, 3Al and 3.82Zr specimens was adjusted by the addition of $\mathrm{Fe}_{2} \mathrm{O}_{3}$. We call the additional oxygen by $\mathrm{Fe}_{2} \mathrm{O}_{3}$ as "excessive oxygen (Ex. O)", more than the amount of oxygen originated from $\mathrm{Y}_{2} \mathrm{O}_{3}$. The specimen compositions listed in Table 1 . The metal, cubic $\mathrm{Y}_{2} \mathrm{O}_{3}$ and $\mathrm{Fe}_{2} \mathrm{O}_{3}$ powders were mixed together, and mechanically-alloyed (MAed) by using a planetary-ball mill with a ball/powder weight ratio 1/10, a rotation speed of 300rpm for 48h, in Ar atmosphere. The balls for MA were made from Fe-Cr stainless steel. A MAed powder was then enveloped in Fe foil and vacuum-shield in a quartz capsule with a piece of $\mathrm{Zr}$ foil to avoid surface oxidation of the powder. A capsule was annealed in a muffle furnace at a temperature of $773 \mathrm{~K}$ to $1423 \mathrm{~K}$ for $4 \mathrm{~h}$. Even the element compositions are adjusted carefully, the contamination of $\mathrm{C}$ and $\mathrm{O}$ is inevitable during the whole process of the specimen preparation. We measured the amount of $\mathrm{C}$ and $\mathrm{O}$ after the specimen preparation by infrared absorption method after combustion and inert gas fusion method, respectively (shown in Table 1). 
Table 1. Target specimen compositions and measured amount of C and O (in wt. \%)

$\begin{array}{lllllllll}\text { Specimen } & \mathrm{Fe} & \mathrm{Cr} & \mathrm{W} & \mathrm{Ti} & \mathrm{Al} & \mathrm{Zr} & \mathrm{Y}_{2} \mathrm{O}_{3} & \text { Ex.O (expected) }\end{array}$

\begin{tabular}{|c|c|c|c|c|c|c|c|c|}
\hline Base & bal. & 15 & 2 & - & - & - & 3.5 & - \\
\hline $1.5 \mathrm{Ti}$ & bal. & 15 & 2 & 1.5 & - & - & 3.5 & $1.0\left(\right.$ as $\left.\mathrm{Y}_{2} \mathrm{Ti}_{2} \mathrm{O}_{7}\right)$ \\
\hline $3 \mathrm{Al}$ & bal. & 15 & 2 & - & 3 & - & 3.5 & 0.75 (as $\mathrm{YAlO}_{3}$ ) \\
\hline $3.82 \mathrm{Zr}$ & bal. & 15 & 2 & - & - & 3.82 & 3.5 & $1.0\left(\right.$ as $\left.\mathrm{Y}_{2} \mathrm{Zr}_{2} \mathrm{O}_{7}\right)$ \\
\hline
\end{tabular}

Specimen $\quad \mathrm{C} \quad \mathrm{O} \quad$ Ex. O (in fact)

\begin{tabular}{|c|c|c|}
\hline Base & 0.20 & 0.87 \\
\hline $1.5 \mathrm{Ti}$ & 0.11 & 1.8 \\
\hline $3 \mathrm{Al}$ & 0.16 & 1.7 \\
\hline $3.82 \mathrm{Zr}$ & 0.15 & 2.0 \\
\hline
\end{tabular}

An annealed powder was put into a silica glass capillary measuring $0.3 \mathrm{~mm}$ internal diameter and measured by Synchrotron-radiation X-ray diffraction and small angle scattering (SR-XRD and SR-SAXS) at BL19B2 beamline in SPring-8 (Hyogo, Japan) with an incident X-ray energy of $30 \mathrm{keV}(\lambda=0.0413 \mathrm{~nm})$. SR-XRD data was taken by using a large Debye-Scherrer camera with radius of $286.5 \mathrm{~nm}$ and an imaging plate (IP) on the $2 \theta$ arm as a detector. The peak of SR-XRD was identified by using the Inorganic Material Database (AtomWork) presented by National Institute for Materials Science 
(NIMS) [23]. SR-SAXS data was taken by using a two-dimensional hybrid pixel array detectors (PILATUS-2M) with the camera length of 3m, corresponding the covered $q$ range of $0.1-5.6 \mathrm{~nm}^{-1}$, where $q$ is the scattering vector described with the scattering angle $\theta$ as $q=|q|=4 \pi \sin \theta / \lambda$. The measurement time of SR-XRD and SAXS was 300 and 60 seconds per one specimen, respectively. Some of the SR-SAXS measurement took 300 seconds to obtain more clear profile. SAXS profile fitting was done based on the lognormal distribution for the spherical particles [24].

3DAP and TEM analysis were carried out for as-MA powder and low-temperature annealed powder. For 3DAP, CAMECA LEAP-4000X HR was used in laser pulsing mode with laser pulse energies of $50 \mathrm{pJ}$ per pulse at a specimen temperature of $\sim 40 \mathrm{~K}$. The 3DAP data were reconstructed with CAMECA IVAS 3.6.10a software and the compositions of each particles are analysed the maximum separation method. Focused ion beam (FIB: FEI Quanta 200 3D) was used to make 3DAP specimens. For TEM, two different machines were used: FEI Titan with an acceleration voltage of $300 \mathrm{kV}$ to analyse the chemical elements of the oxide particles and JEM-2010F with an acceleration voltage of $200 \mathrm{kV}$ to analyse the lattice structure. TEM specimens were fabricated by FIB (JEOL JIB-4600F) with a subsequent low-energy ion milling (Technoorg Linda GENTLE MILL IV8) to remove the damages induced by FIB. The simulated diffraction patterns were constructed using EDA software [25] to analyse the lattice structure.

In order to model the precipitation of oxide particles, thermodynamic calculations were performed using FactSage $^{\mathrm{TM}}$ [26], version 7.1 with SGPS and SGTE databases and some thermodynamic functions described in the literature [27, 28].

\section{Results}


Fig. 1 shows SR-SAXS profiles of all specimens as-MA and annealed at a temperature of 773K to $1423 \mathrm{~K}$. In as-MA specimens except for 3.82Zr, there is a little peak at around $q=1 \mathrm{~nm}^{-1}$. A clear peak appears in all specimens after annealing $773 \mathrm{~K}$ and the peak shifts to lower- $q$ side with increasing the annealing temperature, indicating a growth of some particles. The average radius of the particles in the as-MA specimens with the standard deviation: base, $1.5 \mathrm{Ti}$ and $3 \mathrm{Al}$ are $1.2 \pm 0.96 \mathrm{~nm}, 1.5 \pm 1.4 \mathrm{~nm}$ and $1.4 \pm 1.2 \mathrm{~nm}$, respectively. The average radius of the specimens after annealing with the standard deviation are shown in Fig. 2. All of them are estimated from the fitting of the profiles shown in Fig. 1. There is no significant difference in size among the specimens annealed at $773 \mathrm{~K}$ and $873 \mathrm{~K}$. The average radius of the particles in the $3.82 \mathrm{Zr}$ specimen after annealing at $973 \mathrm{~K}$ become almost twice as large as that after annealing at $873 \mathrm{~K}$, while the average radius of the other specimens does not become so large. The average radius of the oxide particles in all specimens rises more or less as the heat treatment temperature rises. Note that, the average radius of the particles in the base specimen is the smallest of all the specimens after annealing at above 973K. Fig.3 shows SR-XRD profiles of the same specimens as those measured by SR-SAXS. There is a peak at $10.6^{\circ} 2$-theta in all as-MA specimens and a broad shallow peak between $7.5^{\circ}$ to $9.3^{\circ}$ in the as-MA specimens except for 3.82Zr. The peak at $10.6^{\circ}$ 2-theta corresponds the plane (012) or (102) of trigonal $\mathrm{Y}_{2} \mathrm{O}_{3}$ (space group No. 164: $P \overline{3} m 1$ [29]). In the $3.82 \mathrm{Zr}$ specimens there are certain peaks even in as-MA condition and the peaks are getting shaper with increasing annealing temperature. There is no appropriate oxide which exactly match these peaks, however there are many oxides close to the peaks: $\mathrm{Y}_{2} \mathrm{Zr}_{2} \mathrm{O}_{7}$ (space group No. $227: F d \overline{3} m$ [30]), $\mathrm{Y}_{4} \mathrm{Zr}_{3} \mathrm{O}_{12}$ (space group No. 148: $R \overline{3}$ [31]) and $\mathrm{Y}_{1.2} \mathrm{Zr}_{0.6} \mathrm{O}_{3}$ (space group No. 206: $I a \overline{3}[32])$ are at the left-side of the peaks, $\mathrm{Y}_{0.5} \mathrm{Zr}_{0.5} \mathrm{O}_{1.75}$ (space group No. 225: $F m \overline{3} m$ 
[33]) and $\mathrm{Y}_{0.2} \mathrm{Zr}_{0.8} \mathrm{O}_{1.9}$ (space group No. 138: $\mathrm{P} 42$ /nmc [34]) are at the right-side of the peaks. The peaks become sharper with increasing the annealing temperature. The broad shallow peaks between $7.5^{\circ}$ to $9.3^{\circ}$ of the base and $1.5 \mathrm{Ti}$ specimens rise gradually with rising the annealing temperature. Within the rising area of the base, the peaks of monoclinic $\mathrm{Y}_{2} \mathrm{O}_{3}$ (space group No. 12: $C 2 / m$ [35]) and cubic $\mathrm{Y}_{2} \mathrm{O}_{3}$ (space group No. 206: Ia $\overline{3}[36])$ appear at a temperature of $1173 \mathrm{~K}$ to $1423 \mathrm{~K}$. The peaks of monoclinic $\mathrm{Y}_{2} \mathrm{O}_{3}$ appear also in the $1.5 \mathrm{Ti}$ specimens annealed at a temperature of $1073 \mathrm{~K}$ to $1173 \mathrm{~K}$ and the $3 \mathrm{Al}$ specimens annealed at a temperature of $1173 \mathrm{~K}$ to $1423 \mathrm{~K}$. The peaks of $\mathrm{Y}_{2} \mathrm{Ti}_{2} \mathrm{O}_{7}$ (space group No. 227: $F d \overline{3} m$ [37]) appear in the 1.5Ti specimens annealed at a temperature of $1073 \mathrm{~K}$ to $1423 \mathrm{~K}$. In the $3 \mathrm{Al}$ specimens, the peaks of hexagonal $\mathrm{YAlO}_{3}$ (YAH, space group No. 194: $P 6_{3} / m m c$ [38]) appear at a temperature of 1173 to $1423 \mathrm{~K}$, and the peak of $\mathrm{Y}_{4} \mathrm{Al}_{2} \mathrm{O}_{9}$ (YAM, space group No. 14: $P 2_{1} / c$ [39]) appear at $1423 \mathrm{~K}$. In the $3 \mathrm{Al}$ specimens there is no clear rising below the temperature of $1073 \mathrm{~K}$. There are some peaks identified as chromium oxides, $\mathrm{Cr}_{2} \mathrm{O}_{3}$ and $\mathrm{Cr}_{3} \mathrm{O}$, in the $1.5 \mathrm{Ti}$ and $3 \mathrm{Al}$ specimens, respectively.

Fig. 4 shows a STEM-EDS mapping of the 1.5Ti specimen annealed at 873K. There were many small particles distributed densely in the matrix. The small particles distributed on grain-boundaries (traced by yellow lines in HAADF image of Fig. 4) Y, O and Ti are concentrated at the same areas as the particles (pointed by red arrows). Fig. 5a shows a lattice image of a grain in $1.5 \mathrm{Ti}$ annealed at $873 \mathrm{~K}$ (the left) and a FFT image (the right) constructed from the area surrounded by a red square in the lattice image. The simulated diffraction patterns are shown in Fig. 5b. The FFT image in Fig. 5a is composed of matrix identified $[001]_{F e}$. There are also some weak spots pointed by yellow arrows in the FFT 
image. These spots are identified as the spots of $[001]_{Y 2 T i 207}$ traced by red circles on the simulated diffraction pattern in Fig. 5b.

Fig. 6 shows the reconstructed 3DAP maps of the 3Al and 3.82Zr specimens as-MA and annealed at $873 \mathrm{~K}$. $\mathrm{Y}$ and $\mathrm{O}$ distribution is localized in the as-MA specimens. The localized $\mathrm{Y}$ and $\mathrm{O}$ are agglomerated after annealing at 873K. Both $\mathrm{Al}$ and $\mathrm{Zr}$ appear to be condensed at the area which $\mathrm{Y}$ and $\mathrm{O}$ are agglomerated. The localization of $\mathrm{W}$ is also observed in both specimens annealed at $873 \mathrm{~K}$.

\section{Discussion}

\subsection{Distortion of $\mathrm{Y}_{2} \mathrm{O}_{3}$ by MA}

SAXS profile of the as-MA specimens except for 3.82Zr show a peak originated from some particles. On the other hand, XRD of the same specimen does not detect cubic $\mathrm{Y}_{2} \mathrm{O}_{3}$, which is initial powder of this fabrication process, while a broad shallow peak is shown in the profile at the $2 \theta$ range of approximately $7.5^{\circ}$ to $9.3^{\circ}$. For a very fine crystallite less than $100 \mathrm{~nm}$, broadening angle of diffraction $(B)$ should be considered and it is described as well-known Scherrer equation:

$$
B=\frac{0.9 \lambda}{t \cdot \cos \theta}
$$

where $\lambda$ is a wavelength of the $\mathrm{X}$-ray, $t$ is diameter of the crystallite and $\theta$ is angle of diffraction. If cubic $\mathrm{Y}_{2} \mathrm{O}_{3}$ exists as fine particles after MA process and SR-SAXS detected these particles, the value of $B$ for the $\{222\}$ diffraction $(\mathrm{d}=3.061 \AA$ [36] and its $2 \theta=$ $7.74^{\circ}$ ) is calculated as $0.89^{\circ}$ by using the particle radius of $1.2 \mathrm{~nm}$ estimated by the SRSAXS measurement of the base as-MA specimen and the wavelength of $30 \mathrm{keV}$ X-ray of $0.413326 \AA$. The broadening angle of diffraction almost agrees with the rising area at the 
2-theta range of approximately $7.5^{\circ}$ to $9.3^{\circ}$ in Fig. 2, and this interprets the remaining of initial cubic $\mathrm{Y}_{2} \mathrm{O}_{3}$ even after 48h MA. However, the peak corresponded to trigonal $\mathrm{Y}_{2} \mathrm{O}_{3}$ appears in as-MA condition and monoclinic $\mathrm{Y}_{2} \mathrm{O}_{3}$ appears after annealing $1173 \mathrm{~K}$ to $1423 \mathrm{~K}$, both of which cannot exist from the beginning of sample preparation. Even $\mathrm{Y}_{2} \mathrm{O}_{3}$ remained after 48h MA, the crystal structure of cubic $\mathrm{Y}_{2} \mathrm{O}_{3}$ should be highly distorted during MA.

\subsection{Nucleation of the oxide particles}

Fig. 4 and 6 shows that the additive elements, $\mathrm{Ti}, \mathrm{Al}$ and $\mathrm{Zr}$, are concentrated at the area which $\mathrm{Y}$ and $\mathrm{O}$ are agglomerated, even at lower temperatures where the complex oxides are not detected by SR-XRD (except for 3.82Zr). According to Fig. 5, the particle probably has their own lattice identified as $\mathrm{Y}_{2} \mathrm{Ti}_{2} \mathrm{O}_{7}$ at $873 \mathrm{~K}$ although the spots in the FFT image are very weak. These results indicate that oxide particles could precipitate at lower temperatures, but they are highly disordered. The present result agrees with the disordered structure of the oxide particles has been reported by He et al. [10] and the oxide cluster formation has been suggested by a lot of literature [40- 42]. However, According to Fig. 3, Y-Al complex oxides are more difficult to precipitate at lower temperatures. Here we consider a free energy change associated with the nucleation process of an oxide particle, $\Delta G$, which is described by the following well-known equation:

$$
\Delta G=-V \Delta G_{v}+A \gamma+V \Delta G_{s}
$$

where $V$ is a volume of an oxide particle, $\Delta G_{v}$ is the chemical driving force of the oxide formation, $A$ is the area of interface, $\gamma$ is the interfacial energy and $\Delta G_{S}$ is the elastic strain energy of the oxide particle. For an oxide particle which has a spherical shape, Equation (2) will be described as a function of the radius of oxide particle, $r$, and given by: 


$$
\Delta G=-\frac{4}{3} \pi r^{3}\left(\Delta G_{v}-\Delta G_{s}\right)+4 \pi r^{2} \gamma
$$

$\Delta G_{v}$ can be calculated based on the solid solution supersaturation at the equilibrium [43, 44]. Considering the following reaction of $\mathrm{Y}_{2} \mathrm{O}_{3}$ :

$$
2 Y^{\alpha}+3 O^{\alpha}=Y_{2} O_{3}
$$

where the superscript indicates solution in ferrite matrix, $\alpha$. At the equilibrium, $\Delta G_{v}$ can be expressed by the Gibbs free energy of the elements which compose $\mathrm{Y}_{2} \mathrm{O}_{3}$, as:

$$
\begin{aligned}
\Delta^{0} G_{Y_{2} O_{3}} & ={ }^{0} G_{Y_{2} O_{3}}-2^{0} G_{Y}-3{ }^{0} G_{O} \\
& =R T \log \left(a_{Y}^{\alpha^{2}} \cdot a_{O}^{\alpha^{3}}\right)\left[\mathrm{J} \cdot \mathrm{mol}^{-1}\right] \\
& =R T \log \left(a_{Y}^{\alpha^{2}} \cdot a_{O}^{\alpha^{3}}\right) \cdot \rho_{Y_{2} O_{3}} / m_{Y_{2} O_{3}}\left[\mathrm{~J} \cdot \mathrm{m}^{-3}\right]
\end{aligned}
$$

where $R$ is gas constant, $T$ is temperature, $a_{Y}^{\alpha}$ and $a_{O}^{\alpha}$ are activity of $\mathrm{Y}$ and $\mathrm{O}$ in the ferrite matrix, $\rho_{Y_{2} O_{3}}$ and $m_{Y_{2} O_{3}}$ are density and molecular weight of $\mathrm{Y}_{2} \mathrm{O}_{3}$, respectively. In Equation (5), the activity of the $\mathrm{Y}_{2} \mathrm{O}_{3}$ oxide particle is assumed to be 1 . Going back to Equation (3), $\Delta G_{s}$ is described as $\Delta G_{s}=4 \mu \delta^{2}$, where $\mu$ is the shear modulus of the matrix and $\delta=\left(d_{P}-d_{M}\right) / d_{M}$ is the lattice misfit between the oxide particle with an interplanar distance of $d_{P}$ and the matrix with an interplanar distance of $d_{M}$ [45]. $\gamma$ can be calculated based on the Read-Shockley equation of the well-established dislocation model of grain-boundaries, and described as following equations [46]:

$\gamma=E_{0} \cdot \theta(\alpha-\ln \theta)$

$\theta=\frac{b}{h}=\delta$

where $E_{0} \sim 0.1 \mu b, b$ is the Burgers vector for the iron matrix. $\alpha$ is a constant, which depends on the core energy of an individual dislocation and here taken as $1 . \theta$ is the disorientation angle between two grains, which has the same meaning as $\delta$. $\delta$ can be calculated by using some certain orientations and lattice constants reported in the 
literature. Then, the variation in $\Delta G$ with $r$ at selected temperature by assigning the values to Equation (3). Fig. 7a shows the variations in $\Delta G$ with $r$ at $873 \mathrm{~K}$ for some oxides which observed in the present work. The parameters used for the calculations are given in Table 2. The activities are calculated using FactSage ${ }^{\mathrm{TM}}$ software with some thermodynamic functions cited from literature (see Table 2). The detail of the calculations is shown in Supplemental data. We choose YAM for the $3 \mathrm{Al}$ specimen and $\mathrm{Y}_{2} \mathrm{Zr}_{2} \mathrm{O}_{7}$ and $\mathrm{Y}_{4} \mathrm{Zr}_{3} \mathrm{O}_{12}$ for the 3.82Zr specimen because we do not have any appropriate thermodynamic or structural data for the other oxides. According to Fig. 7, the critical radius of $\mathrm{Y}_{2} \mathrm{O}_{3}$, $\mathrm{Y}_{2} \mathrm{Ti}_{2} \mathrm{O}_{7}, \mathrm{Y}_{2} \mathrm{Zr}_{2} \mathrm{O}_{7}$ and $\mathrm{Y}_{4} \mathrm{Zr}_{3} \mathrm{O}_{12}$ range less than $2 \times 10^{-10} \mathrm{~m}$; their critical sizes (diameter) of the precipitates are approximately same as the nearest-neighbour distances of $\mathrm{Y}-\mathrm{O}$ bonds. This can signify that the oxide particles immediately precipitate once the atoms which compose the oxides encounter each other. However, in the above calculations, theoretical calculated values are used for thermodynamic data, and the actual values of activities should be different because the as-MA specimens have many vacancies originated from the defects induced by MA and the defects are not fully recovered after annealing at $823 \mathrm{~K}$ [47]. We have 3DAP data of the 3Al and 3.82Zr specimens, and the actual oxide formation free energy can be obtained measuring the actual concentration of each oxide-forming elements in the particles and the matrix. Equation (3) is now modified as:

$$
\Delta^{0} G_{Y_{4} A l_{2} O_{9}}=R T \ln \left(\frac{c_{Y}^{p^{4}} \cdot c_{A l}^{p^{2}} \cdot c_{O}^{p^{9}}}{c_{Y}^{\alpha^{4}} \cdot c_{A l}^{\alpha}{ }^{2} \cdot c_{O}^{\alpha^{9}}}\right) \cdot \rho_{Y_{4} A l_{2} O_{9}} / m_{Y_{4} A l_{2} O_{9}}\left[\mathrm{~J} \cdot \mathrm{m}^{-3}\right]
$$

where $c^{\alpha}$ or $c^{p}$ are the concentrations of each target element in the matrix or in the particle, respectively. The measured values of $c^{\alpha}$ or $c^{p}$ from 3DAP is listed in Table 3. The concentrations in the matrix and the particles are calculated from the ROI of $10 \times 10$ 
$\times 100 \mathrm{~nm}^{3}$ in Fig. 6 by using the maximum separation method. Fig. 7b shows the variations in modified $\Delta G$ of Fig. 7a with $r$ by using Equation (8) at $873 \mathrm{~K}$ for YAM, $\mathrm{Y}_{2} \mathrm{Zr}_{2} \mathrm{O}_{7}$ and $\mathrm{Y}_{4} \mathrm{Zr}_{3} \mathrm{O}_{12}$. There is no critical radius for $\mathrm{YAM}$ and $\mathrm{Y}_{2} \mathrm{Zr}_{2} \mathrm{O}_{7}$ and their free energies increase indefinitely, which indicates that the two oxides cannot precipitate at 873K. On the other hand, $\mathrm{Y}_{4} \mathrm{Zr}_{3} \mathrm{O}_{12}$ have a critical radius of $0.26 \mathrm{~nm}$. According to Fig. $7 \mathrm{~b}, \mathrm{Y}_{4} \mathrm{Zr}_{3} \mathrm{O}_{12}$ is strongly stable even if the matrix contains many vacancies originated from the defects induced by MA process, and become the most probable oxide formed in the $3.82 \mathrm{Zr}$ specimen after annealing at $823 \mathrm{~K}$.

Table 2. Parameters used for the nucleation model of the oxides observed in the present work.

Value source $\quad$ value ref.

$\begin{array}{ll}\text { Gas constant } & R=8.3144598 \mathrm{~J} \cdot \mathrm{K}^{-1} \cdot \mathrm{mol}^{-1} \\ \text { Shear modulus } & \mu=66.8 \mathrm{GPa}(\text { at } 873 \mathrm{~K}) \\ \text { Burgers vector } & b=2.48 \times 10^{-11} \mathrm{~m} \text { for } a / 2\langle 111\rangle\end{array}$

\section{At $873 \mathrm{~K}$}

Cubic $\mathrm{Y}_{2} \mathrm{O}_{3}$

activity

$$
\begin{gathered}
\Delta^{0} G_{Y_{2} O_{3}}=R T \log \left(a_{Y}^{\alpha^{2}} \cdot a_{O}^{\alpha^{3}}\right) \quad a_{Y}^{\alpha}=2.4895 \times 10^{-18} \\
a_{O}^{\alpha}=8.2008 \times 10^{-24}
\end{gathered}
$$


Lattice constant

$10.604 \times 10^{-10} \mathrm{~m}$

[36]

Density

$\rho_{Y_{2} O_{3}}=5.01 \times 10^{6} \mathrm{~g} \cdot \mathrm{m}^{-3}$

Molecular weight

$m_{Y_{2} O_{3}}=225.809 \mathrm{~g} \cdot \mathrm{mol}^{-1}$

Misfit parameter

$\delta=0.078$

coherent plane

$\{440\}_{Y_{2} O_{3}} I I\{110\}_{\alpha}$

$\mathrm{Y}_{2} \mathrm{Ti}_{2} \mathrm{O}_{7}$

activity

$\Delta^{0} G_{Y_{2} T i_{2} O_{7}}=R T \log \left(a_{Y}^{\alpha^{2}} \cdot a_{T i}^{\alpha{ }^{2}} \cdot a_{O}^{\alpha^{7}}\right) \quad a_{Y}^{\alpha}=7.1334 \times 10^{-15}$

[26, 28]

$$
\begin{aligned}
& a_{T i}^{\alpha}=3.0631 \times 10^{-4} \\
& a_{O}^{\alpha}=4.0651 \times 10^{-26}
\end{aligned}
$$

Lattice constant

$10.083 \times 10^{-10} \mathrm{~m}$

Density

$$
\rho_{Y_{2} T i_{2} O_{7}}=5.00 \times 10^{6} \mathrm{~g} \cdot \mathrm{m}^{-3}
$$

Molecular weight

$$
m_{Y_{2} T i_{2} O_{7}}=385.539 \mathrm{~g} \cdot \mathrm{mol}^{-1}
$$

Misfit parameter

$\delta=-0.129$

coherent plane

$$
\{440\}_{Y_{2} T i_{2} O_{7}}||\{110\}_{\alpha}
$$

$\mathrm{YAM}\left(\mathrm{Y}_{4} \mathrm{Al}_{2} \mathrm{O}_{9}\right)$

activity

$\Delta^{0} G_{Y_{4} A l_{2} O_{9}}=R T \log \left(a_{Y}^{\alpha^{4}} \cdot a_{A l}^{\alpha 2} \cdot a_{O}^{\alpha^{9}}\right) \quad a_{Y}^{\alpha}=8.0120 \times 10^{-11}$

$$
\begin{aligned}
& a_{A l}^{\alpha}=1.9941 \times 10^{-6} \\
& a_{O}^{\alpha}=8.1054 \times 10^{-29}
\end{aligned}
$$

Lattice constant

$$
\mathrm{a}=7.261 \times 10^{-10} \mathrm{~m}
$$




$$
\begin{aligned}
& \mathrm{b}=10.134 \times 10^{-10} \mathrm{~m} \\
& \mathrm{c}=10.9341 \times 10^{-10} \mathrm{~m} \\
& \beta=108.628
\end{aligned}
$$

Density

$$
\rho_{Y_{4} A l_{2} O_{9}}=4.38 \times 10^{6} \mathrm{~g} \cdot \mathrm{m}^{-3}
$$

Molecular weight

$$
m_{Y_{4} A l_{2} O_{9}}=553.579 \mathrm{~g} \cdot \mathrm{mol}^{-1}
$$

Misfit parameter

$$
\delta=0.17
$$

coherent plane

$$
(\overline{1} \overline{2} 4)_{Y_{4} A l_{2} O_{9}} I I(\overline{1} 10)_{\alpha}
$$

$\mathrm{Y}_{2} \mathrm{Zr}_{2} \mathrm{O}_{7}$

activity

$\Delta^{0} G_{Y_{2} Z r_{2} O_{7}}=R T \log \left(a_{Y}^{\alpha^{2}} \cdot a_{Z r}^{\alpha}{ }^{2} \cdot a_{O}^{\alpha 7}\right) \quad a_{Y}^{\alpha}=9.4099 \times 10^{-10}$

$$
\begin{aligned}
& a_{Z r}^{\alpha}=8.2548 \times 10^{-3} \\
& a_{O}^{\alpha}=1.5687 \times 10^{-29}
\end{aligned}
$$

Lattice constant

$10.42 \times 10^{-10} \mathrm{~m}$

Density

$\rho_{Y_{2} Z r_{2} O_{7}}=5.54 \times 10^{6} \mathrm{~g} \cdot \mathrm{m}^{-3}$

Molecular weight

$$
m_{Y_{2} \mathrm{Zr}_{2} \mathrm{O}_{7}}=472.253 \mathrm{~g} \cdot \mathrm{mol}^{-1}
$$

Misfit parameter

$\delta=0.096$

coherent plane

$$
\{440\}_{Y_{2} Z r_{2} O_{7}}||\{110\}_{\alpha}
$$

(present work)

$\mathrm{Y}_{4} \mathrm{Zr}_{3} \mathrm{O}_{12}$

$$
\begin{gathered}
\Delta^{0} G_{Y_{4} Z r_{3} O_{12}}=R T \log \left(a_{Y}^{\alpha^{4}} \cdot a_{Z r}^{\alpha}{ }^{3} \cdot a_{O}^{\alpha 12}\right) \quad a_{Y}^{\alpha}=1 \times 10^{-75} \quad[26,28] \\
a_{Z r}^{\alpha}=5.3365 \times 10^{-3} \\
a_{O}^{\alpha}=6.4040 \times 10^{-2}
\end{gathered}
$$


Lattice constant

$10.42 \times 10^{-10} \mathrm{~m}$

[30]

Density

$\rho_{Y_{4} Z r_{3} O_{12}}=5.28 \times 10^{6} \mathrm{~g} \cdot \mathrm{m}^{-3}$

Molecular weight

$m_{Y_{4} Z r_{3} O_{12}}=821.284 \mathrm{~g} \cdot \mathrm{mol}^{-1}$

Misfit parameter

$\delta=0.022$

coherent plane

$\{4 \overline{3} \overline{2}\}_{Y_{2} Z r_{2} O_{7}}||\{10 \overline{1}\}_{\alpha}$

[56]

Table 3. Concentrations of each target elements measured from 3DAP (in at. \%)

Specimen $\quad c_{Y}^{\alpha} \quad c_{A l}^{\alpha} \quad c_{Z r}^{\alpha} \quad c_{O}^{\alpha} \quad c_{Y}^{p} \quad c_{A l}^{p} \quad c_{Z r}^{p} \quad c_{O}^{p}$

$\begin{array}{lcccccccc}3 \mathrm{Al} & 0.16 & 2.0 & - & 1.0 & 10 & 8.7 & - & 8.8 \\ 3.82 \mathrm{Zr} & 0.4 & - & 1.1 & 2.7 & 9.5 & - & 8.0 & 16\end{array}$

\subsection{Coarsening of the oxide particles}

$\mathrm{Ti}$ and $\mathrm{Zr}$ are well-known as the elements which reduce the size of the oxide particles

[1]. Despite the common knowledge, the present SAXS measurement showed that all reactive elements ( $\mathrm{Ti}, \mathrm{Al}$ and $\mathrm{Zr}$ ) enhance the size of oxide particles than that in the base specimen. Assuming that oxide particles grow following Ostwald ripening during 
annealing and conventionally analysed based on the Lifshitz-Slyosov-Wagner (LSW) theory [57] described by the following equation:

$r^{3}-r_{0}^{3}=K t$

$K=8 \gamma C^{e q} D V_{m}{ }^{2} / 9 R T$

where $r$ and $r_{0}$ are the average radius of the particles after and before coarsening, respectively, and the annealing time $t, \gamma$ is interfacial energy of the particles, $C_{e q}$ is the equilibrium solubility of the elements which compose the particles, $D$ is the diffusivity, $V_{m}$ is the molar volume of the particles, $R$ is gas constant, $T$ is the annealing temperature. If $r_{0}$ is enough to small, $r$ is described from Equation (9) and (10), gives:

$r \sim\left[\frac{8 \gamma C^{e q} D V_{m}^{2}}{9 R T} t\right]^{1 / 3}$

It is difficult to estimate $C^{e q}$ if the particles are composed of several elements. $C^{e q}$ is theoretically described by the solubility products if the precipitate is soluble in the matrix $[57,58]$. However, $\mathrm{Y}$ and $\mathrm{O}$ have very low solubility in the Fe-base bcc matrix $[59,60]$ and their concentration in the present matrix should be saturated. Then we represent the concentration of $\mathrm{Y}$ in the matrix as $C_{Y}^{e q}$ and calculated $C_{Y}^{e q}$ by equilibrium of Fe-15Cr2W-3.5Y on Factsage ${ }^{\mathrm{TM}}$ software [26]. $D$ is determined by the lowest diffusion species among the elements composing the oxide [61], and here represented by the diffusion coefficient of Y [62-64]. Fig. 8 shows the variation of calculated $r$ from Equation (11) for the oxides, considered in the section 4.2, with the given values of $\gamma, C_{Y}^{e q}, D_{Y}$ and $V_{m}$. The parameters are listed in Table 4. According to Fig. 8, the calculation based on the LSW theory does not give so bad agreement with the present results (Fig. 2). The deviation from the experiments should be due to the initial radius of the clusters in the asMA condition, the difference of the diffusion mechanism (the grain-boundary diffusion 
is dominant instead of the lattice diffusion at lower temperatures), and the difference of the precipitate species (especially for 3Al). In the present calculation of Equation (10), $\gamma$ and $V_{m}$ depend on the type of oxide. All complex oxides with adding elements ( $\mathrm{Ti}, \mathrm{Al}$ and $\mathrm{Zr}$ ) will grow faster than $\mathrm{Y}_{2} \mathrm{O}_{3}$, because the higher $\gamma$ and $V_{m}$ of $\mathrm{Y}_{2} \mathrm{Ti}_{2} \mathrm{O}_{7}$, YAM and $\mathrm{Y}_{2} \mathrm{Zr}_{2} \mathrm{O}_{7}$ than that of $\mathrm{Y}_{2} \mathrm{O}_{3}$. The calculated inter facial energies for $\mathrm{Y}_{2} \mathrm{O}_{3}$ and $\mathrm{Y}_{2} \mathrm{Ti}_{2} \mathrm{O}_{7}$ in the present work are different from the analytical values of Ribis et al. [17] after 1573K for $1 \mathrm{~h}$ annealing, which are $350 \mathrm{~mJ} \cdot \mathrm{m}^{-2}$ and $260 \mathrm{~mJ} \cdot \mathrm{m}^{-2}$ for $\mathrm{Y}_{2} \mathrm{O}_{3}$ and $\mathrm{Y}_{2} \mathrm{Ti}_{2} \mathrm{O}_{7}$, respectively. Their interfacial energy of $\mathrm{Y}_{2} \mathrm{Ti}_{2} \mathrm{O}_{7}$ is much lower than that of our present work. It is because we do not consider the shape of the oxide particles, i.e. the anisotropy of elastic strain in the oxide particles. We also calculated with applying the interfacial energy of Ribis et al. and plotted the size of oxide particles in Fig. 8. Although the much smaller interfacial energy is applied, the $\mathrm{Y}_{2} \mathrm{Ti}_{2} \mathrm{O}_{7}$ oxide particles grow faster than the $\mathrm{Y}_{2} \mathrm{O}_{3}$ oxide particles. This indicates that the values of $V_{m}$ are effective. It is difficult to find justifiable reasons for the difference between the present work and lots of literature, however, based on at least the LSW theory, it can be said that the growth of oxide particles is enhanced with the addition of the reactive elements, $\mathrm{Ti}, \mathrm{Al}$ and $\mathrm{Zr}$, by forming the complex oxides. The difference between the present work and lots of literature is the amount of $\mathrm{Y}_{2} \mathrm{O}_{3}$ at the initial process; in the present work, the amount of $\mathrm{Y}_{2} \mathrm{O}_{3}$ is approximately ten times larger than those of the literature. It should be considered the special effect of dilute addition of such reactive elements in the literature. Also, the amount of $\mathrm{Y}_{2} \mathrm{O}_{3}$ should affect $C_{Y}^{e q}$ in Equation (11). According to Boulant et al. [43], who calculated the solubility products of $\mathrm{Y}_{2} \mathrm{O}_{3}$ and $\mathrm{Y}_{2} \mathrm{Ti}_{2} \mathrm{O}_{7}$ in $0.16 w t . \% \mathrm{Y}$ added Fe-14Cr1W ferritic steel, the values of solubility products of $\mathrm{Y}_{2} \mathrm{Ti}_{2} \mathrm{O}_{7}$ and $\mathrm{Y}_{2} \mathrm{O}_{3}$ are very low: $\sim 10^{-}$ 18 and $10^{-38}$ at $1423 \mathrm{~K}$, respectively. These small values should affect $C_{Y}^{e q}$ in Equation 
(11) and $r$ will be much lower than those in the present work, and also deduce the reduction of the radius of the oxide particles by the addition of Ti.

Table 4. The values used on the calculation of Ostwald ripening.

\begin{tabular}{|c|c|c|c|c|c|}
\hline & Cubic $\mathrm{Y}_{2} \mathrm{O}_{3}$ & $\mathrm{Y}_{2} \mathrm{Ti}_{2} \mathrm{O}_{7}$ & YAM & $\mathrm{Y}_{2} \mathrm{Zr}_{2} \mathrm{O}_{7}$ & $\mathrm{Y}_{4} \mathrm{Zr}_{3} \mathrm{O}_{12}$ \\
\hline$V_{m}\left[\mathrm{~m}^{3} \cdot \mathrm{mol}^{-1}\right]$ & $4.51 \times 10^{-5}$ & $7.71 \times 10^{-5}$ & $1.26 \times 10^{-4}$ & $8.52 \times 10^{-5}$ & $1.56 \times 10^{-4}$ \\
\hline \multicolumn{6}{|c|}{$\gamma\left[\mathrm{J} \cdot \mathrm{m}^{-2}\right]^{*}$} \\
\hline Temperature [K] & Cubic $\mathrm{Y}_{2} \mathrm{O}_{3}$ & $\mathrm{Y}_{2} \mathrm{Ti}_{2} \mathrm{O}_{7}$ & YAM & $\mathrm{Y}_{2} \mathrm{Zr}_{2} \mathrm{O}_{7}$ & $\mathrm{Y}_{4} \mathrm{Zr}_{3} \mathrm{O}_{12}$ \\
\hline 773 & 0.48 & 0.68 & 0.81 & 0.55 & 0.18 \\
\hline 873 & 0.46 & 0.65 & 0.78 & 0.53 & 0.18 \\
\hline 973 & 0.44 & 0.62 & 0.74 & 0.51 & 0.17 \\
\hline 1073 & 0.42 & 0.59 & 0.71 & 0.48 & 0.16 \\
\hline 1173 & 0.40 & 0.56 & 0.67 & 0.46 & 0.15 \\
\hline 1423 & 0.34 & 0.49 & 0.59 & 0.40 & 0.13 \\
\hline Temperature [K] & $C_{Y}^{e q}\left[\mathrm{~mol}^{-1}\right]$ & $D_{Y}\left[\mathrm{~m}^{2} \cdot \mathrm{s}^{-1}\right]$ & & & \\
\hline 773 & $4.75 \times 10^{-10}$ & $6.15 \times 10^{-26}$ & & & \\
\hline 873 & $6.06 \times 10^{-9}$ & $1.27 \times 10^{-23}$ & & & \\
\hline 973 & $5.03 \times 10^{-8}$ & $8.77 \times 10^{-22}$ & & & \\
\hline 1073 & $2.84 \times 10^{-7}$ & $2.75 \times 10^{-20}$ & & & \\
\hline 1173 & $1.13 \times 10^{-6}$ & $4.80 \times 10^{-19}$ & & & \\
\hline 1423 & $1.98 \times 10^{-5}$ & $1.05 \times 10^{-16}$ & & & \\
\hline
\end{tabular}

*Temperature dependence of $\gamma$ is calculated from the variation of shear modulus $\mu$ with temperature [48].

\section{Conclusion}

The effect of $\mathrm{Ti}, \mathrm{Al}$ and $\mathrm{Zr}$-addition on the nucleation and the growth mechanisms of Fe-15Cr ODS ferritic steel is studied in the present work. SR-SAXS and XRD shows that cubic $\mathrm{Y}_{2} \mathrm{O}_{3}$ exist but highly distorted after MA. TEM and 3DAP shows that the additive elements, $\mathrm{Ti}, \mathrm{Al}$ and $\mathrm{Zr}$, are concentrated at the area which $\mathrm{Y}$ and $\mathrm{O}$ are agglomerated, 
even at lower temperatures where the complex oxides are not detected by SR-XRD (except for 3.82Zr). The critical radius of nucleation at 873K from theoretical calculation is close to the size of the molecule for the oxides, however, the oxides are difficult to precipitate at lower temperatures except for $\mathrm{Y}_{4} \mathrm{Zr}_{3} \mathrm{O}_{12}$ because of the effect of MA. The massive addition of $\mathrm{Y}_{2} \mathrm{O}_{3}$ affects the growing of the oxide particles, and the reactive elements enhance the growth of oxide particles because of the large interfacial energy and the molar volume of the complex oxides than those of cubic $\mathrm{Y}_{2} \mathrm{O}_{3}$.

\section{Acknowledgement}

This study supported by MEXT/JSPS KAKENHI Grant Number JP26820325. The synchrotron radiation experiments were performed at the BL19B2 of SPring-8 with the approval of the Japan Synchrotron Radiation Research Institute (JASRI) (Proposal No. 2015A1669); the SAXS and XRD measurements supported. by M. Satou and K. Osaka, respectively. 3DAP analysis was carried out at the International Research Center for Nuclear Materials Science, Institute for Materials Research, Tohoku University. The TEM works were conducted at “Joint-use Facilities: Laboratory of Nano-Micro Material Analysis”, Hokkaido University, supported by ” Nanotechnology Platform” Program of the Ministry of Education, Culture, Sports, Science and Technology (MEXT), Japan. 


\section{References}

[1] S. Ukai, M. Harada, H. Okada, M. Inoue, S. Nomura, S. Shikakura, K. Asabe, T. Nishida and M. Fujiwara, "Alloying design of oxide dispersion for long life FBRs core materials strengthened ferritic steel,” J. Nucl. mater., vol. 204, p. 65, 1993.

[2] S. Ukai, S. Mizuta, M. Fujiwara, T. Okuda and T. Kobayashi, "Development of 9Cr-ODS Martensitic Steel Claddings for Fuel Pins by means of Ferrite to Austenite Phase Transformation," J. Nucl. Sci. Tech., vol. 39, no. 7, pp. 778-788, 2002.

[3] P. Dubuisson, Y. d. Carlan, V. Garat and M. Blat, "ODS Ferritic/martensitic alloys for Sodium Fast Reactor fuel pin cladding,” J. Nucl. Mater., vol. 428, no. 13, pp. 6-12, 2012.

[4] S. Ukai and M. Fujiwara, "Perspective of ODS alloys application in nuclear environments,” J. Nucl. Mater., Vols. 307-311, no. 1, pp. 749-757, 2002.

[5] R. Lindau, A.Möslang, M. Rieth, M. Klimiankou, E. Materna-Morris, A. Alamo, A.-A. Tavassoli, C. Cayron, A.-M. Lancha, P. Fernandez, N. Baluc, R. Schäublin, E. Diegele, G. Filacchioni, J. Rensman, B. Schaaf, E. Lucon and W. Dietz, "Present development status of EUROFER and ODS-EUROFER for application in blanket concepts,” Fus. Eng. Des., Vols. 75-79, pp. 989-996, 2005.

[6] Z. Oksiuta, P. Olier, Y. d. Carlan and N. Baluc, "Development and characterisation of a new ODS ferritic steel for fusion reactor application,” $J$. Nucl. Mater., vol. 393, pp. 114-119, 2009.

[7] N. Baluc, J. Boutard, S. Dudarev, M. Rieth, J. B. Correia, B. Fournier, J. Henry, F. Legendre, T. Leguey, M. Lewandowska, R. Linday, E. Marquis, A. Muñoz, B. Radiguet and Z. Oksiuta, "Review on the EFDA work programme on nanostructured ODS RAF steels,” J. Nucl. Mater., vol. 417, pp. 149-153, 2011.

[8] S. Ukai, N. Oono, S. Ohtsuka, T. Kaito, K. Sakamoto, T. Torimaru, A. Kiimura and S. Hayashi, "Development of FeCrAl-ODS Steels for ATF Cladding," Proc. Light Water Reactor (LWR) Fuel Performance Meeting (TOP FUEL) 2016, 2016.

[9] S. Kim, S. Ohtsuka, T. Kaito, S. Yamashita, M. Inoue, T. Asayama and T. Shobu, "Formation of nano-size oxide particles and $\delta$-ferrite at elevated temperature in 9Cr-ODS steel,” J. Nucl. Mater., vol. 417, no. 1-3, pp. 209-212, 2011.

[10] P. He, T. Liu, A. Möslang, R. Lindau, R. Ziegler, J. Hoffmann, P. Kurinskiy, L. Commin, P. Vladimirov, S. Nikitenko and M. Silveir, "XAFS and TEM studies of the structural evolution of yttrium-enriched oxides in nanostructured ferritic alloys fabricated by a powder metallurgy process," Mater. Chem. Phys., vol. 136, pp. 990-998, 2012. 
[11] N. OONO and S. Ukai, "Precipitation of Oxide Particles in Oxide Dispersion Strengthened (ODS) Ferritic Steels," Materials Transactions, vol. 59, no. 10, pp. 1651-1658, 2018.

[12] M. Alinger, G. Odette and D. Hoelzer, "The development and stability of Y-Ti-O nanoclusters in mechanically alloyed Fe-Cr based ferritic alloys,” J. Nucl. Mater., Vols. 239-333, pp. 382-386, 2004.

[13] D. Hoelzer, J. Bentley, M. Sokolov, M. Miller, G. Odette and M. Alinger, "Influence of particle dispersions on the high-temperature strength of ferritic alloys,” J. Nucl. Mater., Vols. 367-370, pp. 166-172, 2007.

[14] S. Ukai and S. Ohtsuka, "Nano-mesoscopic structure control in 9Cr-ODS ferritic steels,” Energ. Mater., vol. 2, no. 1, pp. 26-35, 2007.

[15] I. Kim, B. Choi, C. Kang, T. Okuda, P. Maziasz and K. Miyahara, "Effect of Ti and $\mathrm{W}$ on the Mechanical Properties and Microstructure of $12 \%$ Cr Base Mechanical-alloyed Nano-sized ODS Ferritic Alloys," ISIJ International, vol. 43, no. 10, pp. 1640-1646, 2003.

[16] H. Sakasegawa, F. Legendre, L. Boulanger, M. Brocq, L. Chaffron, T. Cozzika, J. Malaplate, J. Henry and Y. d. Carlan, "Stability of non-stoichiometric clusters in the MA957 ODS ferrtic alloy,” J. Nucl. Mater., vol. 417, pp. 229-232, 2011.

[17] J. Ribis and Y. d. Carlan, "Interfacial strained structure and orientation relationships of the nanosized oxide particles deduced from elasticity-driven morphology in oxide dispersion strengthened materials," Acta Mater., vol. 60, pp. 238-252, 2012.

[18] A. Hirata, T. Fujita, Y. Wen, J. Schneibel, C. Liu and M. Chen, "Atomic structure of nanoclusters in oxide-dispersion-strengthened steels," Nature Mater., vol. 10, no. 12, pp. 922-926, 2011.

[19] M. Brocq, B. Radiguet, S. Poissonnet, F. Cuvilly, P. Pareige and F. Legendre, "Nanoscale characterization and formation mechanism of nanoclusters in an ODS steel elaborated by reactive-inspired ball-milling and annealing,” J. Nucl. Mater., vol. 409, pp. 80-85, 2011.

[20] S. Rogozhkin, N. N. Orlov, A. Nikitin, A. Aleev, A. Zaluzhnyi, M. Kozodaev, R. Lindau, A. Möslang and P. Vladimirov, "Nanoscale characterization of $13.5 \% \mathrm{Cr}$ oxide dispersion strengthened steels with various titanium concentrations," Inorg. Mater. Appl. Res., vol. 6, no. 2, pp. 151-155, 2015.

[21] S. Liu, G. Odette and C. Segre, "Evidence for core-shell nanoclusters in oxygen dispersion strengthened steels measured using X-ray absorption spectroscopy,” $J$. Nucl. Mater., vol. 445, pp. 50-56, 2014. 
[22] Y. Jiang, J. Smith and G. Odette, "Formation of Y-Ti-O nanoclusters in nanostructured ferritic alloys: A first-principles study,” Phys. Rev. B, vol. 79, p. 064103, 2009.

[23] Materials Database Group, "Inorganic Material Database (AtomWork)," Nation. Inst. Mater. Sci., 06 2010. [Online]. Available: http://crystdb.nims.go.jp/index_en.html. [Accessed 06 2017].

[24] Y. Oba, S. Koppoju, M. Ohnuma, T. Murakami, H. Hatano, K. Sasakawa, A. Kitahara and J. Suzuki, "Quantitative Analysis of Precipitate in Vanadiummicroalloyed Medium Carbon Steels Using Small-angle X-ray and Neutron Scattering Methods," ISIJ International, vol. 51, no. 11, pp. 1852-2858, 2011.

[25] T. Kogure, "Geometry of Electron Diffraction and Its Calculation," Microscopy (Japanese), vol. 50, no. 1, pp. 1-5, 2015.

[26] C. W. Bale, E. Bélisle, P. Chartrand, S. A. Decterov, G. Eriksson, K. Hack, I. H. Jung, Y. B. Kang, J. Melançon, A. D. Pelton, C. Robelin and S. Petersen, "FactSage thermochemical software and databases - recent developments," Calphad, vol. 33, no. 2, pp. 295-311, 2009.

[27] T. Adylov, G. Voronov, E. Mansurova, L. M. Sigalov and E. Urazaeva, "The Y2O3-Al2O3 System Above 1473 K," Russ. J. Inorg. Chem., vol. 33, pp. 10621063, 1988.

[28] T. Schaedler, O.Fabrichanaya and C. Levi, "Phase equilibria in the TiO2-YO1.5ZrO2 system," J. Europ. Ceram. Soc., vol. 28, pp. 2509-2520, 2008.

[29] M. Foëx and J.-P. Traverse, "Étude à haute température des transformations allotropiques des sesquioexydes d'yttrium, d'erbium et de thulium," Comptes rendus hebdomadaires des séances de l'Académie des sciences, vol. 261, no. 9, pp. 2490-2493, 1965.

[30] V. Buntushkin, I. Romanovich and N. Timofeeva, "HIGH-TEMPERATURE MICROHARDNESS AND CERTAIN PROPERTIES OF REFRACTORY OXIDES," Inorg. Mater., vol. 7, no. 9, pp. 1456-1457, 1971.

[31] V. Red'ko and L. Lopato, "MAGNETIC SUSCEPTIBILITY OF M4ZR3O12 AND M4HF3O12 (M-RARE-EARTH ELEMENT)," Inorg. Mater., vol. 27, pp. 1495-1497, 1991.

[32] I. Maister, L. LOPATO, Z. ZAITSEVA and A. SHEVCHENKO, "INTERACTION IN THE ZRO2-Y2O3-SC2O3 SYSTEM AT 1300-1900C," Inorganic materials, vol. 27, no. 11, pp. 1997-2000, 1991. 
[33] D.-J. Kim, S.-H. Hyun, S.-G. Kim and M. Yashima, "Effective Ionic Radius of Y3+ Determined from Lattice Parameters of Fluorite-Type HfO2 and ZrO2 Solid Solutions," J. Am. Ceram. Soc., vol. 77, no. 2, pp. 597-599, 1994.

[34] L. Sharygin, V. Galkin, S. Vovk and Y. Dorofeev, "SOLID SOLUTIONS OF THE ZRO2-Y2O3 SYSTEM PRODUCED BY THE SOL-GEL METHOD," Inorganic Materials, vol. 27, no. 2, pp. 221-224, 1991.

[35] V. Skrikanth, A. Sato, J. Yoshimoto, J. Kim and T. Ikegami, "Synthesis and crystal structure study of Y2O3 high-pressure polymorph," Crys. Res. Tech., vol. 29, no. 7, pp. 981-984, 1994.

[36] E. L. L. K. V. Z. Z. Andrievskaya, Inorg. Mater., vol. 32, pp. 645-653, 1996.

[37] V. Dolgikh and E. Lavat, Russ. J. Inorg. Chem., vol. 36, pp. 1389-1392, 1991.

[38] F. Bertaut, J. Mareschal and C. R. Hebd, Seances Acad. Sci., vol. 257, pp. 867870, 1963.

[39] Y. Zhou, X. Lu, H. Xiang and Z. Feng, "Preparation, mechanical, and thermal properties of a promising thermal barrier material: Y4Al2O9," J. Adv. Cer., vol. 4, no. 2, pp. 94-102, 2015.

[40] D. Larson, P. Maziasz, I. Kim and K. Miyahara, "Three-dimensional atom probe observation of nanoscale titanium-oxygen clustering in an oxide-dispersionstrengthened Fe-12Cr-3W-0.4Ti+Y2O3 ferritic alloy,” Scripta Mater., vol. 44, pp. 359-364, 2001.

[41] M. Miller, K. Russell and D. Hoelzer, "Characterization of precipitates in MA/ODS ferritic alloys,” J. Nucl. Mater., vol. 351, pp. 261-268, 2006.

[42] A. London, S. Santra, S. Amirthapandian, B. Panigrahi, R. Sarguna, S. Balaji, R. Vijay, C. Sundar, S. Lozano-Perez and C. Grovenor, "ffect of Ti and Cr on dispersion, structure and composition of oxide nano-particles in model ODS alloys,” Acta Mater., vol. 97, pp. 223-233, 2015.

[43] X. Boulant, M. Perez, D. Fabrègue, S. Cazottes and Y. de Carlan, "Characterization and modeling of oxides precipitation in ferritic steels during fast non-isothermal consolidation," Acta Mater., vol. 107, pp. 390-403, 2016.

[44] E. J. Pavlina, J. G. Speer and C. J. Van Tyne, "Equilibrium solubility products of molybdenum carbide and tungsten carbide in iron,” Scripta Mater., vol. 66, pp. 243-246, 2012.

[45] P. Dou, A. Kimura, R. Kasasda, T. Okuda, M. Inoe, S. Ukai, S. Ohnuki, T. Fujisawa and F. Abe, "TEM and HRTEM study of oxide particles in an Al-alloyed 
high-Cr oxide dispersion strengthened steel with Zr addition," J. Nucl. Mater. 444, pp. 441-453, 2014.

[46] N. Oono, Q. Tang and S. Ukai, "Oxide particle refinement in Ni-based ODS alloy," Mater. Sci. Eng. A, vol. 649, pp. 250-253, 2016.

[47] T. Schuler, M. Nastar and F. Soisson, "Vacancy-induced dissolution of precipitates in out-of-equilibrium systems: A test case of $\mathrm{FeX}(\mathrm{X}=\mathrm{C}, \mathrm{N}, \mathrm{O})$ alloys," Physical Review B, vol. 95, no. 1, p. 1-13, 2017.

[48] B. Latella and S. Humphries, "Young's modulus of a 2.25Cr-1Mo steel at elevated temperature,” Scripta Mater., vol. 51, pp. 635-639, 2004.

[49] E. Elsukov, E. Voronina and V. Barinov, J. Magn. Magn. Mater., vol. 115, pp. 271-280, 1992.

[50] G. Skandan, C. Foster, H. Frase, M. N. Ali, J. C. Parker and H. Hahn, "Phase characterization and stabilization due to grain size effects of nanostructured Y2O3," Nanostructured Materials, vol. 1, no. 4, pp. 313-322, 1992.

[51] P. Villars \& K. Cenzual (Eds.), "Y2Ti2O7 Crystal Structur: Datasheet from "PAULING FILE Multinaires Edition - 2012",” Springer - Verlag Berlin Hidelberg \& Material Phases Data System (MDPS), Switzerland \& National Institute for Materials Science (NIMS), Japan, 2016. [Online]. Available: https://materials.springer.com/isp/crystallographic/docs/sd_1903246. [Accessed 1812 2018].

[52] K. A. Persson, "Materials Data on Y4Al2O9 (SG: 14)," Materials Project, United States, 2016. [Online]. Available: doi:10.17188/1264857. [Accessed 1812 2018].

[53] N. Oono, K. Nakamura, S. Ukai, T. Kaito, T. Torimaru, A. Kimura and S. Hayashi, "Oxide particle coarsening at temperature over $1473 \mathrm{~K}$ in 9CrODS steel," Nucl. Mater. Energy, vol. 9, pp. 342-345, 2016.

[54] P. Villars and K. Cenzual, "YAlO3; YAP (YAlO3 rt) Crystal Structure: Datasheet from "PAULING FILE Multinaries Edition - 2012” in SpringerMaterials," Springer-Verlag Berlin Heidelberg \& Material Phases Data System (MPDS), Switzerland \& National Institute for Materials Science (NIMS), Japan, 2012. [Online]. Available: https://materials.springer.com/isp/crystallographic/docs/sd_1924024. [Accessed 1812 2018].

[55] K. A. Persson, "Materials Data on Y4Zr3O12 (SG:2)," Materials Project. United States, 2014. [Online]. Available: doi:10.17188/1282854. [Accessed 2812 2018]. 
[56] N. H. Oono, S. Ukai, S. Hayashi, S. Ohtsuka, T. Kaito, A. Kimura, T. Torimaru and K. Sakamoto, "Growth of oxide particles in FeCrAl- oxide dispersion strengthened steels at high temperature," Journal of Nuclear Materials journal, vol. 493, pp. 180-188, 2017.

[57] C. Wagner, "Theorie der Alterung von Niederschlägen durch Umlösen (OstwaldReifung)," Zeitschrift für Elektrochemie, vol. 65, no. 7, pp. 581-591, 1961.

[58] P. R. Rios, “Quasi-stoichiometric coarsening of f.c.c. carbides in microalloyed austenite containing niobium and vanadium,” Mater. Sci. Eng. A, vol. 171, no. 12, pp. 175-179, 1993.

[59] W. Zhang, G. Liu and K. Han, "Fe-Y (Iron-Yttrium)," in Binary Alloy Phase Diagrams Vol. 2. Fe-Ru to Zn-Zr, Metals Park, Ohio, American Society for Metals, 1986, pp. 1793-1794.

[60] L. S. Darken and R. W. Gurry, “The System Iron-Oxygen. II. Equilibrium and Thermodynamics of Liquid Oxide and Other Phases,” J. Am. Chem. Soc., vol. 68, no. 5, p. 798-816, 1946.

[61] M.J.Alinger, "On the Formation and Stability of Nanometer Scale Precipitates in Ferritic Alloys during Processing and High Temperature Service," University of California Santa Barbara, California, 2004.

[62] J. Hirvonen and J. Räisänen, "Diffusion of aluminum in ion-implanted alpha iron," J. Appl. Phys., vol. 53, pp. 3314-3316, 1982.

[63] D. Murali, B. Panigrahi, M. Valsakumar and C. Sundar, "Diffusion of Y and Ti/Zr in bcc iron: A first principles study," J. Nucl. Mater., vol. 419, pp. 208-212, 2011.

[64] P. Klugkist and C. Herzig, "Tracer diffusion of titanium in $\alpha$-iron," Phys. Stat. Sol. (a), vol. 148, p. 413, 1995. 


\section{Captions of the figures}

Figure 1. SR-SAXS profile of as-MA and annealed powders.

Figure 2. Variation of average radius with annealing temperature analysed by SR-SAXS profile shown in Fig.1.

Figure 3. SR-XRD profile of as-MA and annealed powders.

Figure 4. STEM-EDS mapping of $1.5 \mathrm{Ti}$ specimen annealed at $873 \mathrm{~K}$.

Figure 5. HRTEM analysis of 1.5Ti specimen annealed at 873K: (a) Lattice image (left) and its FFT image (right), (b) simulated diffraction patterns of the matrix (left) and $\mathrm{Y}_{2} \mathrm{Ti}_{2} \mathrm{O}_{7}$ (right).

Figure 6. 3DAP image of $3 \mathrm{Al}$ and 3.82Zr specimens as-MA and annealed at $873 \mathrm{~K}$.

Figure 7. Free energy of nucleation in the function of the radius of the particle for the oxides.

Figure 8. Variation of the calculated radius of the particles based on the LSW theory with annealing temperature. 
$\checkmark \mathrm{Cr}_{23} \mathrm{C}_{6} \quad \nabla \mathrm{Cr}_{2} \mathrm{O}_{3} \quad \triangle \mathrm{Cr}_{3} \mathrm{O} \quad-\mathrm{Y}_{2} \mathrm{O}_{3}\left(\right.$ monocinic) $\square \mathrm{Y}_{2} \mathrm{O}_{3}$ (cubic) $\quad$ I $\mathrm{Y}_{2} \mathrm{Ti}_{2} \mathrm{O}_{7}$

- $\mathrm{YAIO}_{3}(\mathrm{YAH}) \quad \circ \mathrm{YAlO}_{3}(\mathrm{YAP}) \quad \triangle \mathrm{Y}_{4} \mathrm{Al}_{2} \mathrm{O}_{9}(\mathrm{YAM}) \quad \& \mathrm{Y}_{2} \mathrm{Zr}_{2} \mathrm{O}_{7}, \mathrm{Y}_{4} \mathrm{Zr}_{3} \mathrm{O}_{12}, \mathrm{Y}_{1.2} \mathrm{Zr}_{0.6} \mathrm{O}_{3}+\mathrm{Y}_{0.5} \mathrm{Zro}_{0.5} \mathrm{O}_{1.75} \mathbf{x} \mathrm{Y}_{0.2} \mathrm{Zro}_{0.8} \mathrm{O}_{1.9}$

Base

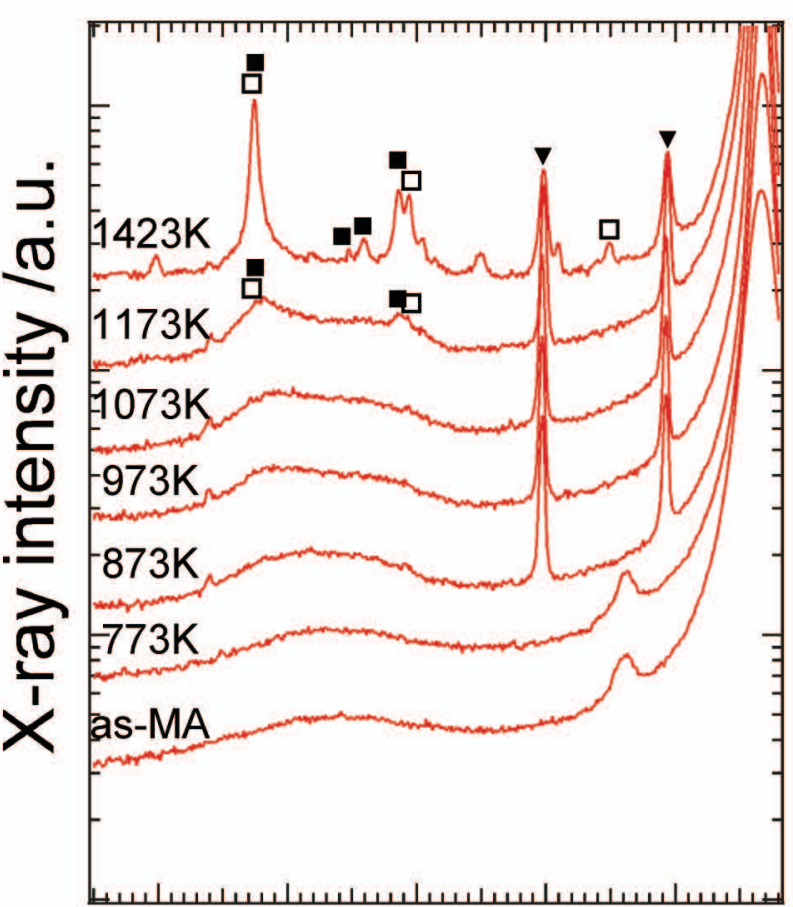

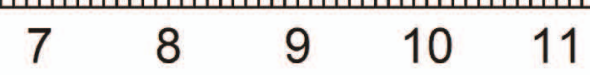

Diffraction angle, $2 \theta^{\circ}$
1.5Ti

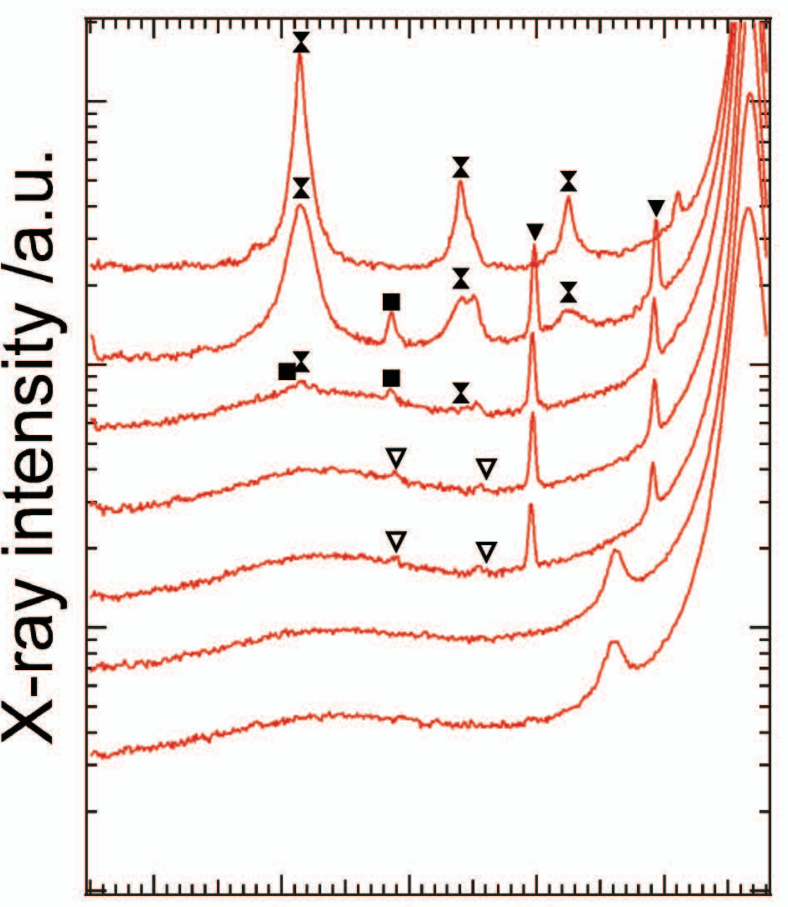

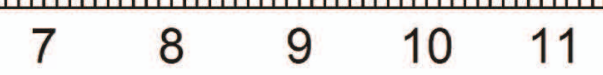

Diffraction angle, $2 \theta^{\circ}$
3Al

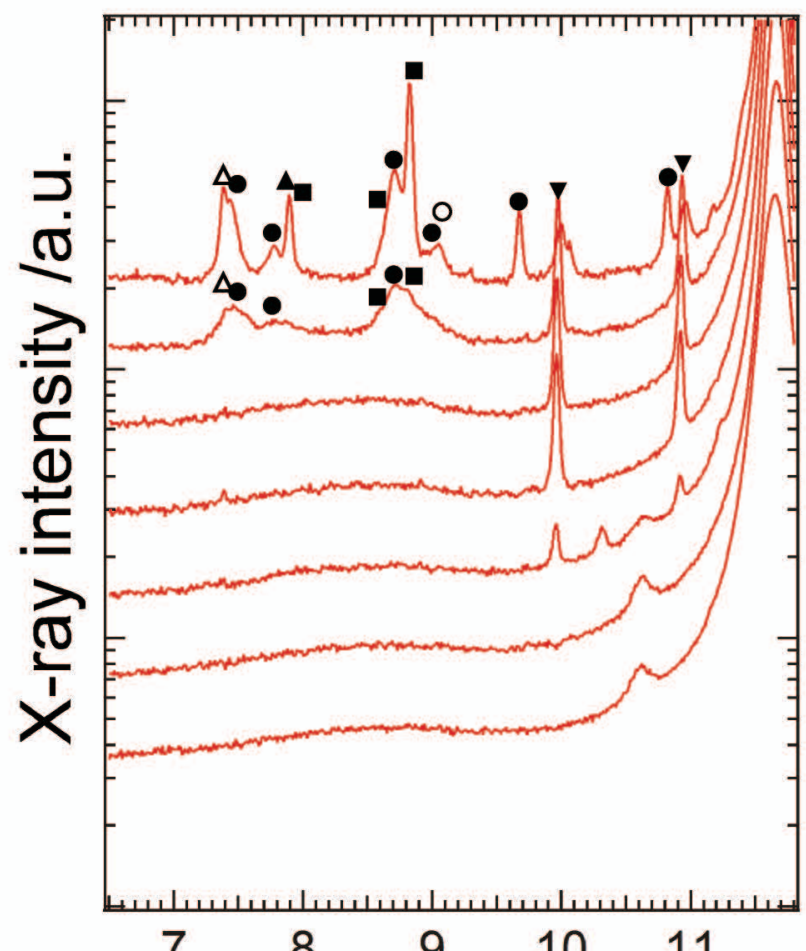

Diffraction angle, $2 \theta /^{\circ}$
$3.82 \mathrm{Zr}$

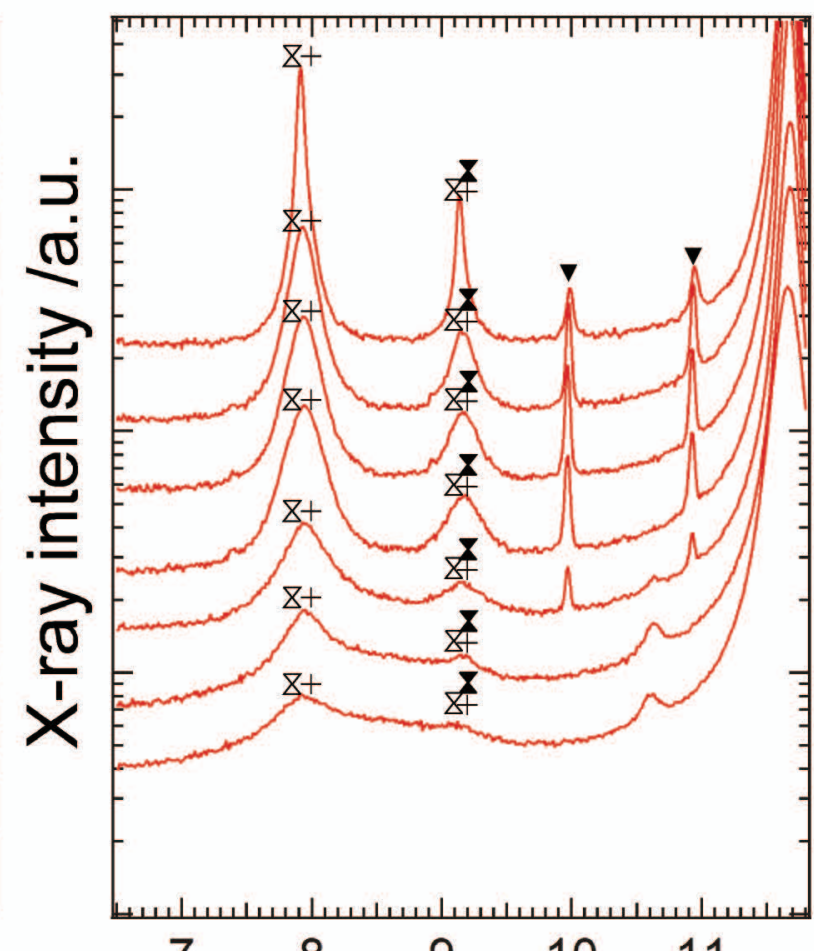

Diffraction angle, $2 \theta l^{\circ}$ 


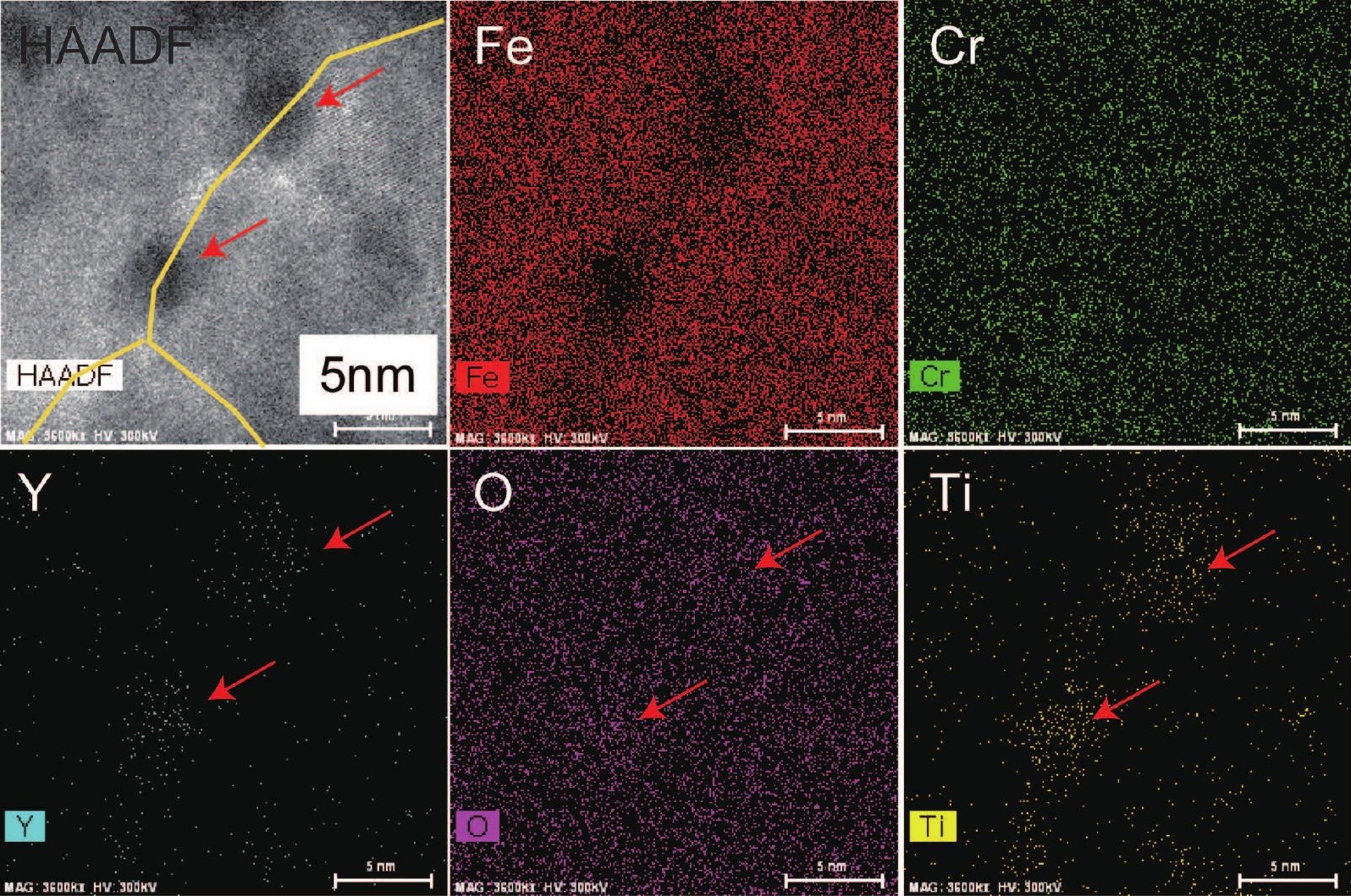



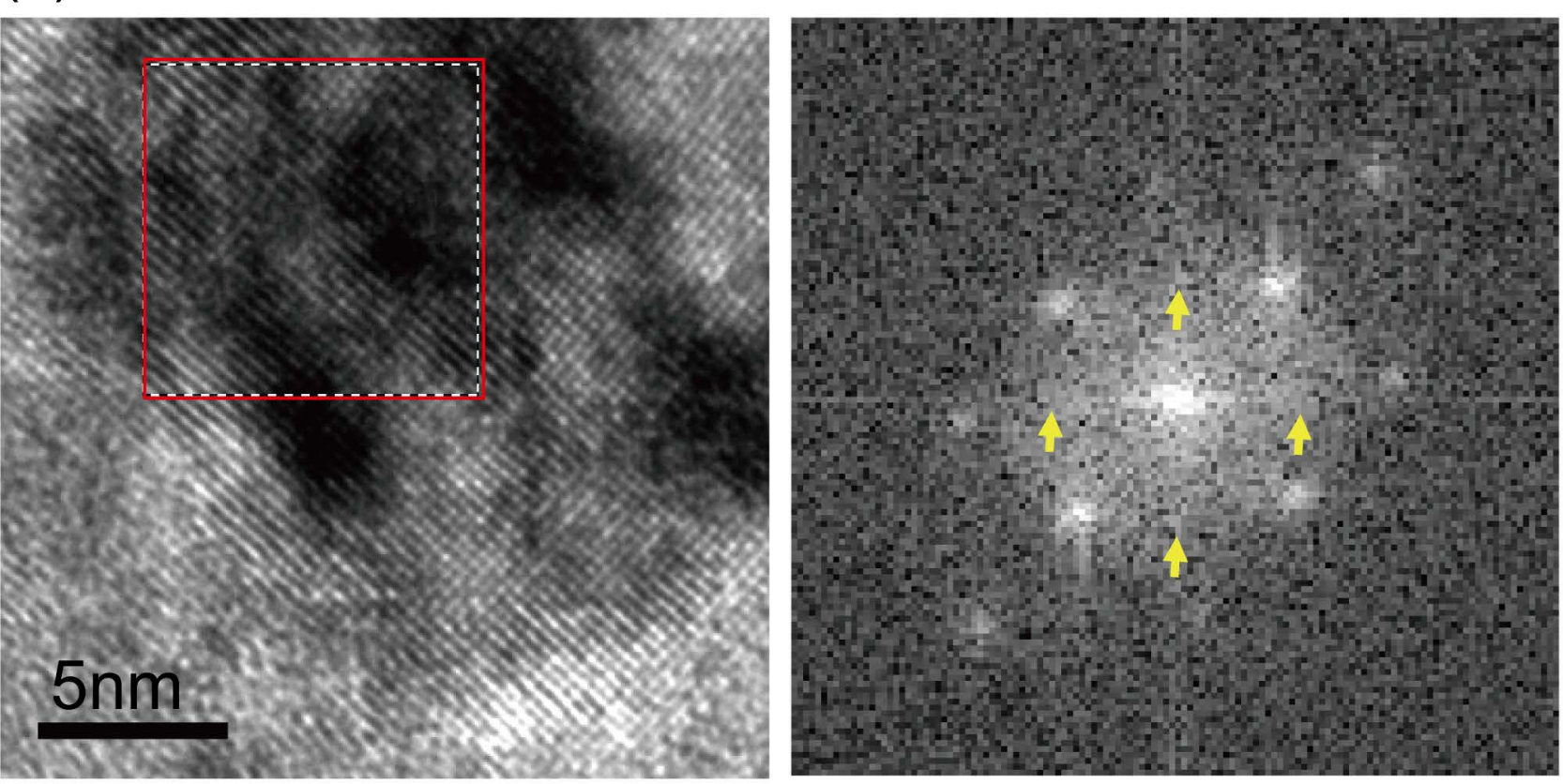

(b)

Matrix

$\mathrm{Y}_{2} \mathrm{Ti}_{2} \mathrm{O}_{7}$

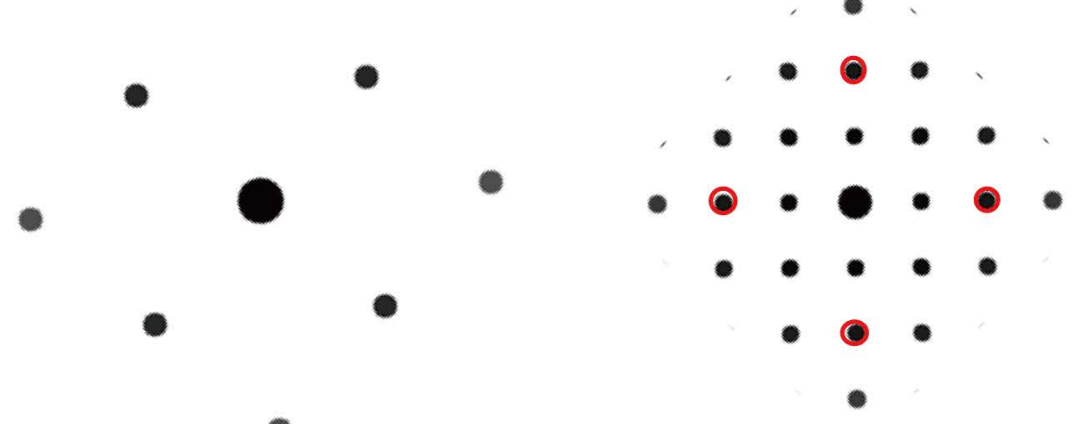


3Al, as MA

$\mathrm{Fe}$ 20 $\mathrm{Cr}$ W

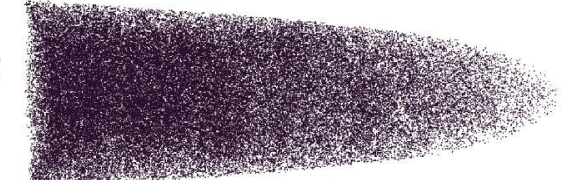

Al

20 1020
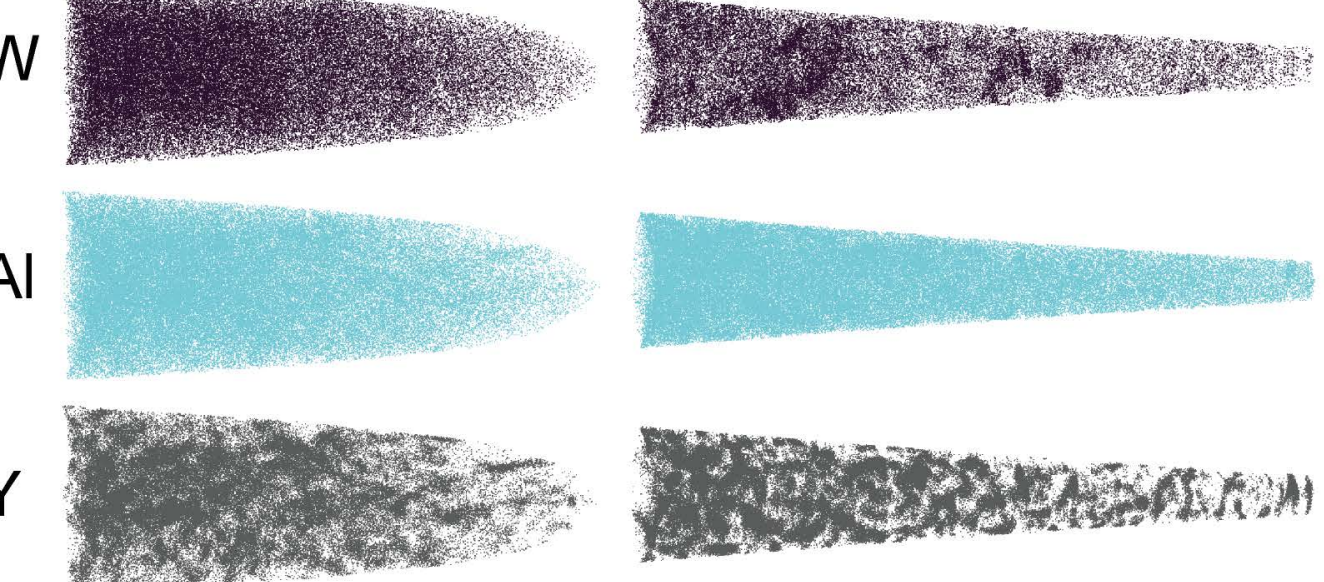

0

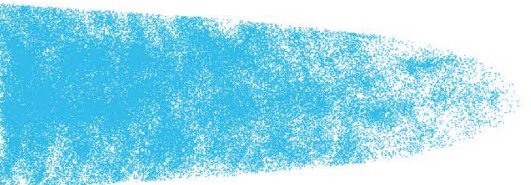

$\mathrm{Fe}$

$\mathrm{Cr}$

$\mathrm{Zr}$

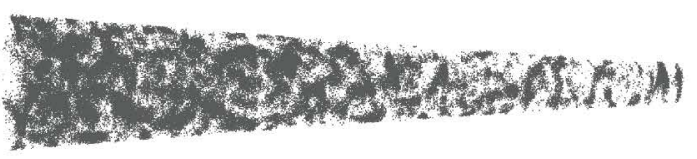

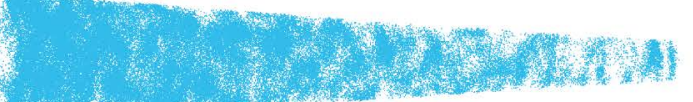

X 010

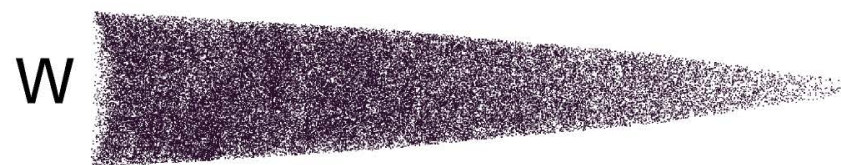

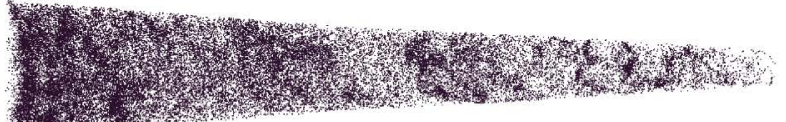

(1)

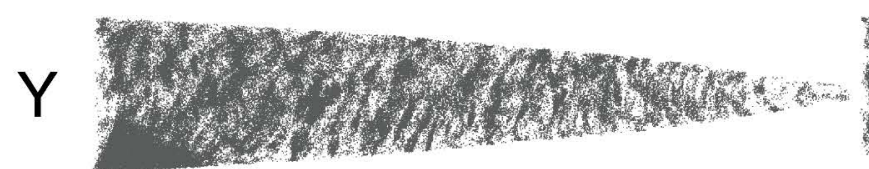

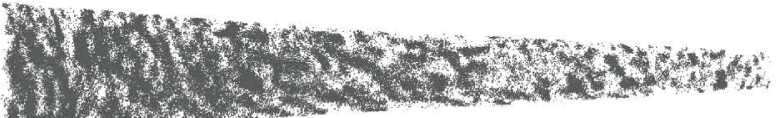

$\mathrm{O}$

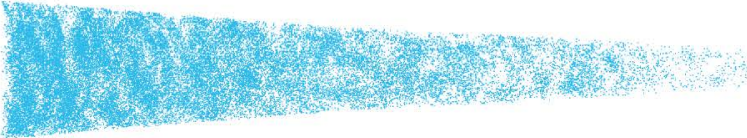


(b)

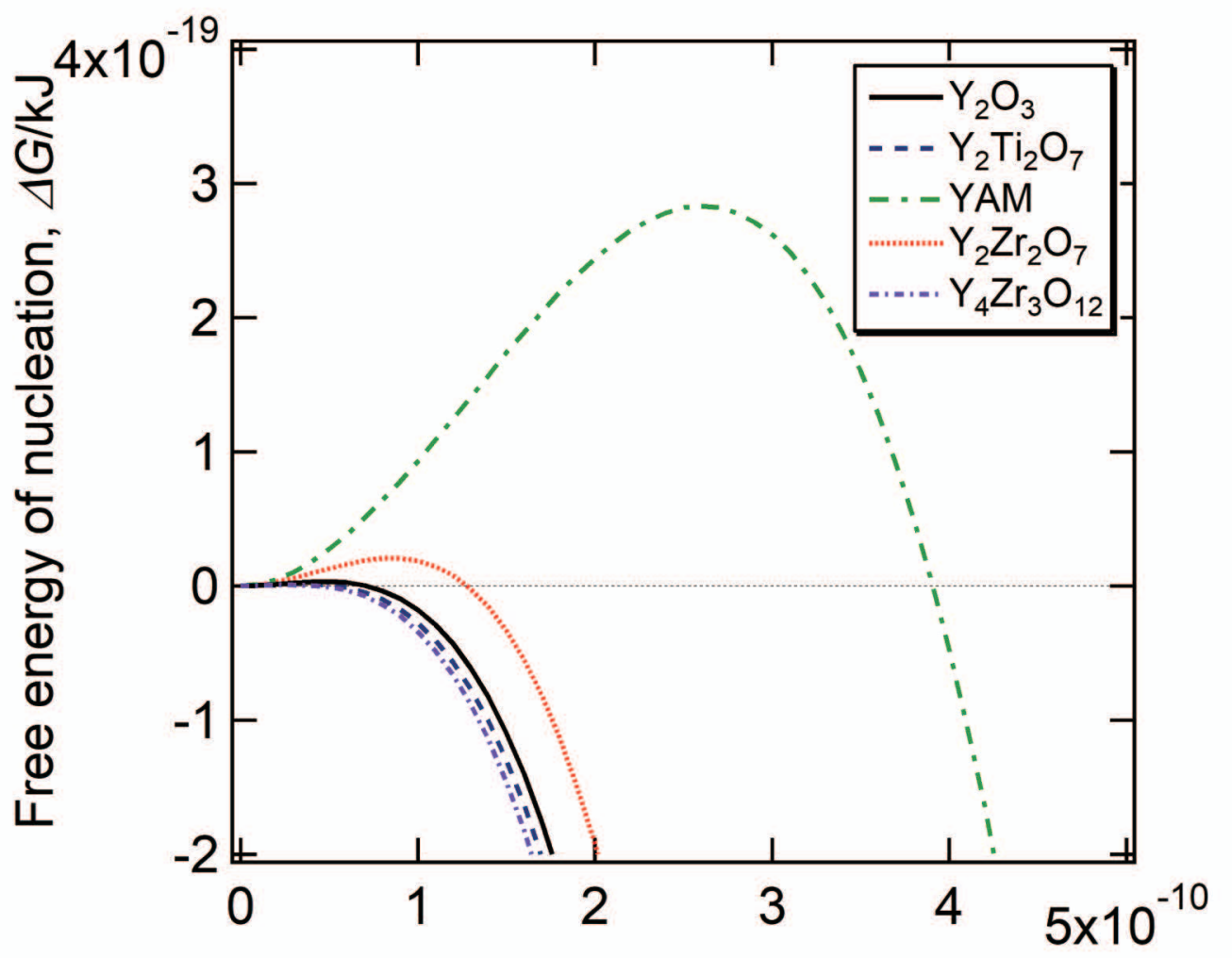

Radius of the particle, $r / m$

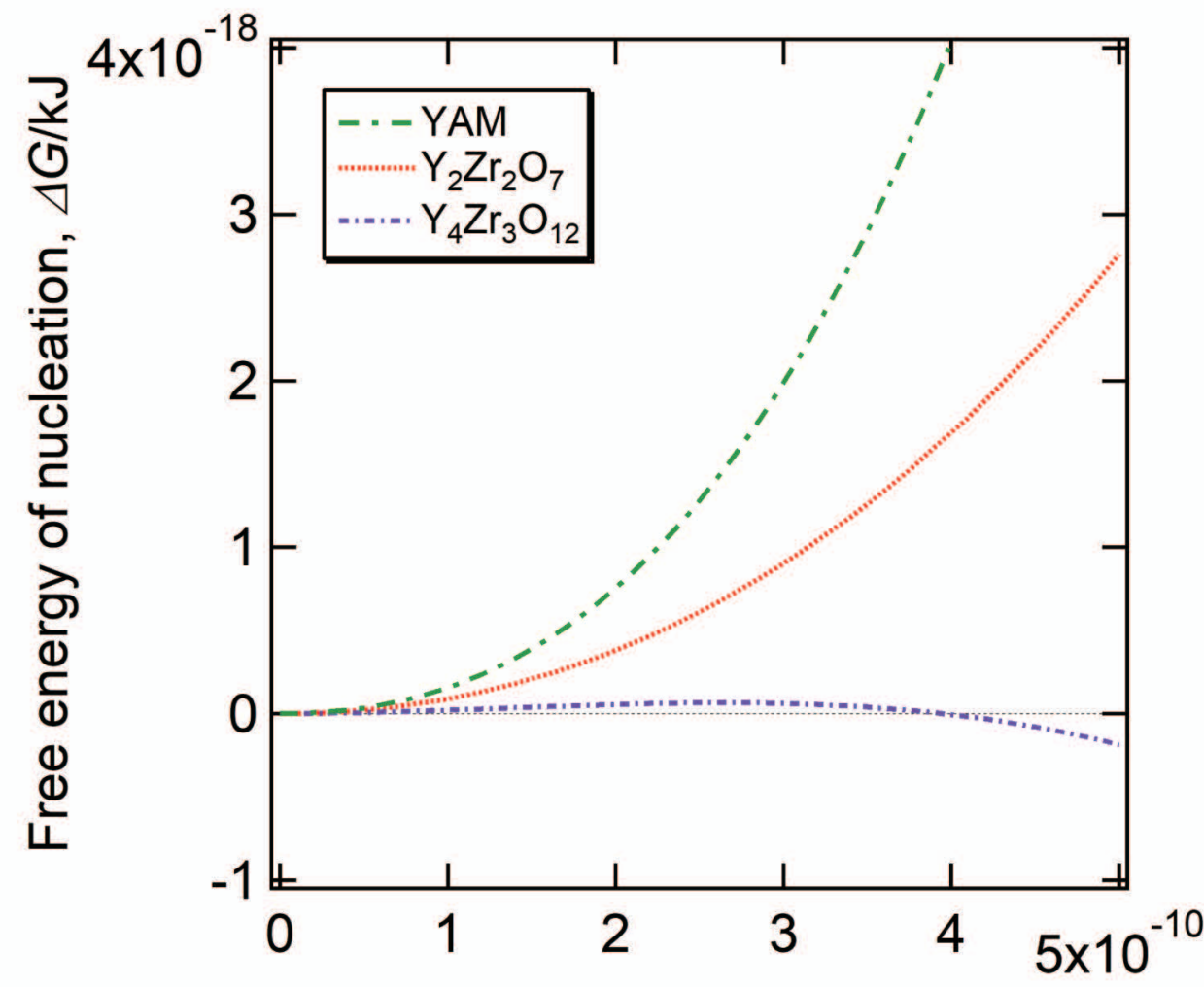

Radius of the particle, $r / m$ 


$\begin{array}{llll}\text { FactSage } & 7.1 & \\ \mathrm{~T} & = & 873 & \mathrm{~K} \\ \mathrm{P} & = & 1 & \mathrm{~atm} \\ \mathrm{~V} & = & 0 & \mathrm{dm} 3\end{array}$

STREAM CONSTITUENTS AMOUNT/mol

$\begin{array}{ll}\mathrm{Fe} & 7.91 \mathrm{E}-01 \\ \mathrm{Cr} & 1.60 \mathrm{E}-01 \\ \mathrm{~W} & 6.04 \mathrm{E}-03 \\ \mathrm{Y} & 1.72 \mathrm{E}-02 \\ 0 & 2.58 \mathrm{E}-02\end{array}$

EQUIL AMOUNT MOLE FRACTION ACTIVITY

PHASE: BCC_A2 mol

$\begin{array}{llll}\mathrm{Cr}: \mathrm{Va} & 1.60 \mathrm{E}-01 & 1.67 \mathrm{E}-01 & 6.32 \mathrm{E}-01 \\ \mathrm{Fe}: \mathrm{Va} & 7.91 \mathrm{E}-01 & 8.26 \mathrm{E}-01 & 8.66 \mathrm{E}-01 \\ \mathrm{0}: \mathrm{Va} & 4.92 \mathrm{E}-24 & 5.14 \mathrm{E}-24 & 8.20 \mathrm{E}-24 \\ \mathrm{~W}: \mathrm{Va} & 6.04 \mathrm{E}-03 & 6.31 \mathrm{E}-03 & 7.30 \mathrm{E}-01 \\ \mathrm{Y}: \mathrm{Va} & 3.28 \mathrm{E}-24 & 3.42 \mathrm{E}-24 & 2.49 \mathrm{E}-18 \\ \text { TOTAL: } & 9.57 \mathrm{E}-01 & 1.00 \mathrm{E}+00 & 1.00 \mathrm{E}+00 \\ \text { System } & \text { component } & \text { Mole fraction } & \text { Mass fraction } \\ & \text { W } & 6.31 \mathrm{E}-03 & 2.07 \mathrm{E}-02 \\ & \mathrm{Y} & 3.42 \mathrm{E}-24 & 5.44 \mathrm{E}-24 \\ & \mathrm{Fe} & 0.82625 & 0.82384 \\ & \mathrm{Cr} & 0.16744 & 0.15544 \\ & 0 & 5.14 \mathrm{E}-24 & 1.47 \mathrm{E}-24\end{array}$

Curie temperature $=987.76 \mathrm{~K}$

Average magnetic moment/atom $=1.7153$

ページ(1) 
Equilib_Y203@873K3. 5. txt

\begin{tabular}{|c|c|c|c|c|}
\hline & $\mathrm{mol}$ & ACTIVITY & & \\
\hline 03Y2_S1 (s) & 8. $61 \mathrm{E}-03$ & 1. $00 \mathrm{E}+00$ & & \\
\hline $\mathrm{Cp}$ & $H$ & $S$ & $G$ & V \\
\hline J. K-1 & $\mathrm{J}$ & J. K-1 & $J$ & $\mathrm{dm} 3$ \\
\hline
\end{tabular}
4. $29 \mathrm{E}+01$
4. $97 \mathrm{E}+03$
6. $40 \mathrm{E}+01$
$-5.09 E+04$
0. $00 \mathrm{E}+00$

$\mathrm{Cp}$

J. K-1

BCC_A2

4. $18 \mathrm{E}+01$

03Y2_S1 (s)

1. $10 \mathrm{E}+00$

H

J

2. $08 \mathrm{E}+04$

$-1.58 \mathrm{E}+04$

$S$

G

J. K-1

6. $21 \mathrm{E}+01$

1. $94 \mathrm{E}+00$

$-1.75 \mathrm{E}+04$

Show only stable phases option in effect

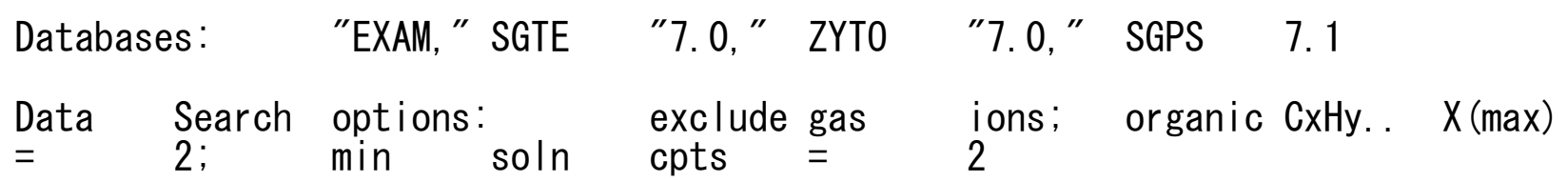

